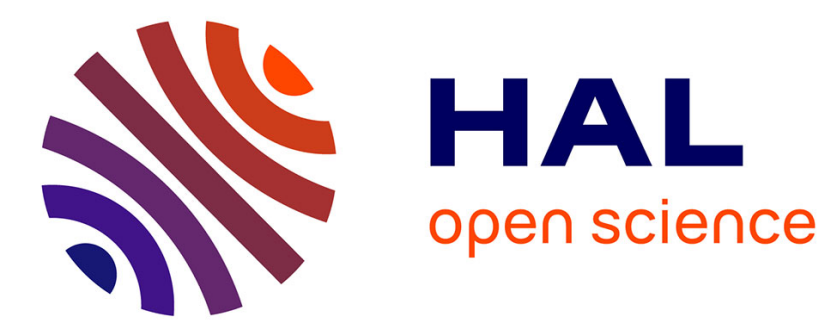

\title{
Taxation and Income Distribution Dynamics in a Neoclassical Growth Model
}

\author{
Cecilia Garcìa-Peñalosa, Stephen J. Turnovsky
}

\section{To cite this version:}

Cecilia Garcìa-Peñalosa, Stephen J. Turnovsky. Taxation and Income Distribution Dynamics in a Neoclassical Growth Model. 2008. halshs-00341001

\section{HAL Id: halshs-00341001 https://shs.hal.science/halshs-00341001}

Preprint submitted on 24 Nov 2008

HAL is a multi-disciplinary open access archive for the deposit and dissemination of scientific research documents, whether they are published or not. The documents may come from teaching and research institutions in France or abroad, or from public or private research centers.
L'archive ouverte pluridisciplinaire HAL, est destinée au dépôt et à la diffusion de documents scientifiques de niveau recherche, publiés ou non, émanant des établissements d'enseignement et de recherche français ou étrangers, des laboratoires publics ou privés. 


\section{TAXATION AND INCOME DISTRIBUTION DYNAMICS IN A NEOCLASSICAL GROWTH MODEL}

Cecilia García-Peñalosa

Stephen J. Turnovsky

November 2008

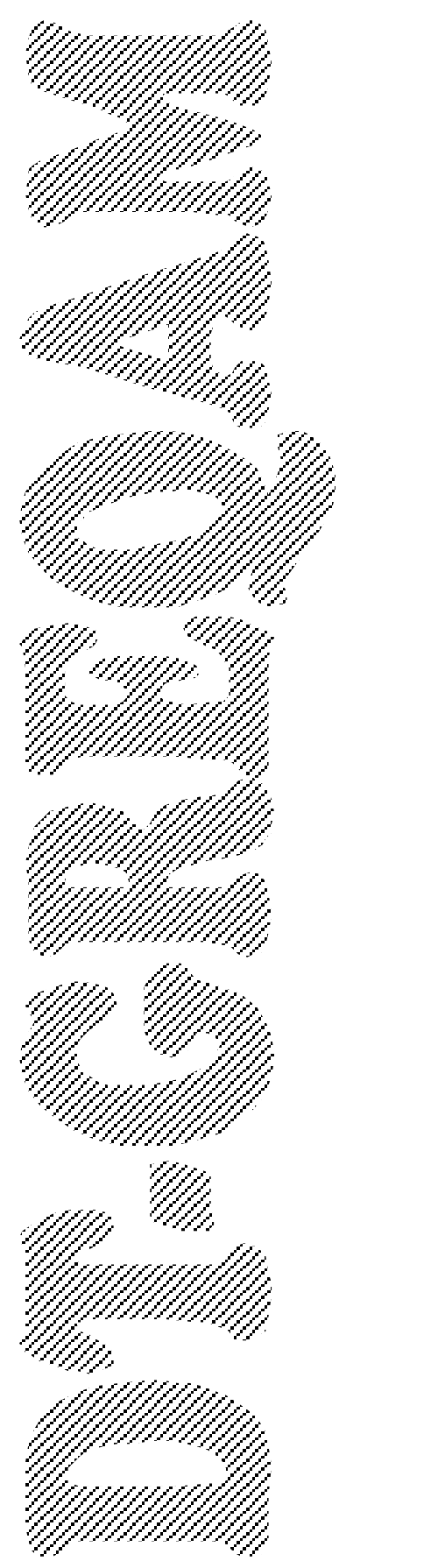




\title{
Taxation and Income Distribution Dynamics in a Neoclassical Growth Model ${ }^{*}$
}

\author{
Cecilia García-Peñalosa \\ CNRS and GREQAM \\ Stephen J. Turnovsky \\ University of Washington, Seattle
}

July 2008

\begin{abstract}
We examine how changes in tax policies affect the dynamics of the distributions of wealth and income in a Ramsey model in which agents differ in their initial capital endowment. The endogeneity of the labor supply plays a crucial role in determining inequality, as tax changes that affect hours of work will affect the distribution of wealth and income, reinforcing or offsetting the direct redistributive impact of taxes. Our results indicate that tax policies that reduce the labor supply are associated with lower output but also with a more equal distribution of after-tax income. We illustrate these effects by examining the impact of recent tax changes observed in the US and in European economies.
\end{abstract}

JEL Classification Numbers: D31, O41

Key words: taxation; wealth distribution; income distribution; endogenous labor supply; transitional dynamics.

\footnotetext{
* The paper has benefited from seminar presentations at the Free University of Berlin, at GREQAM, and at Washington State University, as well as presentations at the conference "Growth with Heterogeneous Agents: Causes and Effects of Inequality", Marseille, June 2008, the $14^{\text {th }}$ Conference on Computation in Economics and Finance, Paris, June 2008, and the $3^{\text {rd }}$ Workshop on Macroeconomic Dynamics, held in Melbourne, July 2008. Comments received at these various presentations are gratefully acknowledged. In particular, we thank Jess Benhabib, Julio Davila, and Roger Farmer for their comments. García-Peñalosa would like to acknowledge the support received from the Institut d'Economie Publique (IDEP), Marseille. Turnovsky's research was supported in part by the Castor endowment at the University of Washington.
} 


\section{Introduction}

The role of taxation in the neoclassical growth model has been extensively studied, and the impact of different taxes on both the long-run equilibrium and transitional dynamics is well documented. ${ }^{1}$ However, the implications of the tax structure for the distributions of income and wealth have received much less attention. Two notable exceptions are Krusell, Quadrini, and RiosRull (1996) and Correia (1999). Krusell, Quadrini, and Rios-Rull examine the efficiency and distributional effects of switching from an income to a consumption tax. Correia proposes a methodology to rank alternative aggregate equilibria in terms of their distributional implications by examining the effect on factor prices. In this paper we examine the distributional effects of taxes on capital income, labor income, and consumption, characterizing both the steady state distributions of income and wealth, as well as their transitional dynamics in response to expenditure and tax changes. This is important, since as we shall demonstrate below, fiscal policy typically involves sharp tradeoffs between its effects on the level of activity and its distributional consequences. ${ }^{2}$

We employ a Ramsey model in which agents differ in their initial endowments of capital (wealth). Representing preferences by a utility function that is homogeneous in consumption and leisure allows aggregation as in Gorman (1953) or Eisenberg (1961), and generates a representativeconsumer characterization of the macroeconomic equilibrium. This enables us to address distributional issues sequentially, thereby increasing dramatically the analytical tractability. First, the dynamics of the aggregate stock of capital and labor supply are jointly determined, independently of distributional considerations. The cross-sections of individual wealth and income and their dynamics are then characterized in terms of the aggregate magnitudes.

A crucial mechanism determining the evolution of income inequality is the relationship we derive between agents' relative wealth (capital) and their relative allocation of time between work and leisure. This relationship is fundamental and has a simple intuition. Wealthier agents have a lower marginal utility of wealth. They therefore choose to increase consumption of all goods

\footnotetext{
${ }^{1}$ See, for example, Judd (1985), Chamley (1986), Lucas (1990), Stokey and Rebelo (1991), Turnovsky (2000), and Ladrón-de-Guevara et al. (2002).

${ }^{2}$ In García-Peñalosa and Turnovsky (2007) we discuss these tradeoffs within the framework of a simple endogenous growth model.
} 
including leisure, and reduce their labor supply. Indeed, the role played by labor supply in this model is analogous to its role in other models of capital accumulation and growth, where it provides the crucial mechanism by which demand shocks influence the rate of capital accumulation. ${ }^{3}$ This mechanism is also central to empirical models of labor supply based on intertemporal optimization; see e.g. MaCurdy (1981).

There is substantial empirical evidence in support of this negative relationship between wealth and labor supply. Holtz-Eakin, Joulfaian, and Rosen (1993) provided evidence to suggest that large inheritances decrease labor participation. Cheng and French (2000) and Coronado and Perozek (2003) use data from the stock market boom of the 1990s to study the effects of wealth on labor supply and retirement, finding a substantial negative effect on labor participation. Algan, Chéron, Hairault, and Langot (2003) employ French data to analyze the effect of wealth on labor market transitions, and find a significant wealth effect on the extensive margin of labor supply. Overall, these studies and others provide compelling evidence in support of the wealth-leisure mechanism being emphasized in this paper.

We characterize the time paths of the distributions of wealth and income, as well as their steady-state distributions, and examine their responses to changes in tax rates. In general we show how the evolution of wealth inequality is driven by the dynamics of aggregate labor supply (leisure) through its response to the accumulation of aggregate capital stock. In particular, economy-wide accumulation of capital is associated with a reduction in wealth inequality, as wealthier agents, choosing to enjoy more leisure, accumulate capital at slower rates. This in turn then drives the evolution of pre-tax income distribution through its impacts on the relative capital income and relative labor income. In addition to being driven by these same determinants, post-tax income inequality is also dependent on the direct redistributive effects associated with taxes on labor and capital income. To illustrate these channels we analyze the comparative effects of raising alternative tax rates to finance a given increase in government spending on goods, on the one hand, versus financing transfers, on the other. In all cases we find that the income distribution effects dominate

\footnotetext{
${ }^{3}$ For example, in the standard Ramsey model, government consumption expenditure will generate capital accumulation if and only if labor is supplied elastically. With inelastic labor supply it will simply crowd out an equivalent amount of private consumption. The key factor is the wealth effect and the impact this has on the labor-leisure choice, as emphasized by both Ortigueira (2000) and Turnovsky (1995).
} 
the wealth accumulation effects. One consequence of this is that the effects of alternative income taxes on both pre-tax and post-tax income distribution depends critically upon how the resulting revenue is spent.

As a specific example, consider the impact of a higher tax on labor income. The aggregate effect is to reduce labor supply, capital stock, and total output and therefore to raise wealth inequality. While it reduces the aggregate labor supply, the tax on labor income reduces that of the capital-rich by more than that of the capital-poor. This results in a more dispersed distribution of labor incomes and, since these are negatively correlated with capital endowments, tends to reduce pre-tax income inequality. But in addition, the direct redistributive effect from a higher tax on labor income tends to increase post-tax income inequality for a given degree of pre-tax income inequality. If the revenues are rebated neutrally, post-tax income inequality still declines, but if they are spent on a utility-enhancing public good, this effect may dominate and post-tax income inequality may actually rise. The responses of pre-tax and post-tax income inequality are reversed in the case of a tax on capital income.

In our final illustration of the model, we apply it to the recent employment-income distribution experiences of the United States, France and Germany. These economies have adopted very different tax structures and have followed very different time paths with respect to employment and income inequality. While a comprehensive comparison involves a wide range of issues not addressed in our framework, nevertheless we find that the present model helps shed some light on the differences. In particular, the higher tax rates on labor income imply both lower working hours and a more equal distribution of income, consistent with the recent French experience.

Our paper contributes to the recent literature characterizing distributional dynamics in growth models. $^{4}$ This question was first examined in Stiglitz (1969) using a form of the Solow model. Recently, an extensive literature has examined the dynamics of the wealth distribution. One approach has considered economies with ex-ante identical agents and uninsurable, idiosyncratic shocks. ${ }^{5}$ An alternative approach has been to assume that agents differ in their initial capital

\footnotetext{
${ }^{4}$ See Bertola, Foellmi, and Zweimüller (2006) for a survey.

${ }^{5}$ See, for example, Krusell and Smith (1998), Castañeda, Díaz-Giménez, and Rios-Rull (1998), and Díaz, Pijoan-Mas, and Rios-Rull (2003) and Wang (2007).
} 
endowments, as we do in our model. ${ }^{6}$ Our paper follows Caselli and Ventura (2000), who study the dynamics of wealth and income distribution in the Ramsey model, though they restrict their analysis to exogenous labor supply, and do not consider the impact of tax policies. Closely related is Benhabib and Bisin (2006), who also examine the distributive impact of taxes and derive explicit expressions for the distribution of wealth. The analytical frameworks are, however, rather different. They consider an overlapping generations setup in which agents differ in their degree of altruism, and focus on the role of the intergenerational transmissions of wealth and state taxation in generating an empirically plausible distribution of wealth. In contrast, we abstract from these aspects by considering infinitely-lived agents, and center our analysis around the endogeneity of the labor supply, the way in which it is affected by taxation, and its impact on both wealth and income distributional dynamics.

Our work is also related to the recent literature on taxation, growth, and distribution. Several papers have examined the relationship between inequality and growth when capital markets are imperfect, and assessed under what circumstances redistributive taxation can lead to both faster growth and a more equal distribution of income. ${ }^{7}$ Credit constraints imply that redistribution can create new investment opportunities or improve incentives, thus increasing the accumulation of physical or human capital. By adopting a Ramsey framework we are implicitly assuming perfect capital markets, and hence consider a different role of taxation.

The paper is organized as follows. Section 2 describes the economy and derives the macroeconomic equilibrium. Section 3 characterizes the distributions of wealth and income and derives the main results of the paper. Section 4 derives the effects of changes in tax rates on the long-run distributions of wealth and income, which are then illustrated in Section 5 with a number of numerical examples. Section 6 concludes, while insofar as possible the technical details are relegated to an Appendix.

\footnotetext{
${ }^{6}$ See Chatterjee (1994), Chatterjee and Ravikumar (1999), Sorger (2000), Maliar and Maliar (2001), Alvarez-Peláez and Díaz (2005), and Obiols-Homs and Urrutia (2005)

${ }^{7}$ See Aghion, Caroli and García-Peñalosa (1999) for a survey.
} 


\section{The Analytical Framework}

Aggregate output is produced by a single representative firm in accordance with the neoclassical production function

$$
Y=F(K, L) \quad F_{L}>0, F_{K}>0, F_{L L}<0, F_{K K}<0, F_{L K}>0
$$

where, $K, L$ and $Y$ denote the per capita stock of capital, labor supply and output. The wage rate, $w$, and the return to capital, $r$, are determined by the marginal physical products of labor and capital,

$$
\begin{array}{ll}
w(K, L)=F_{L}(K, L) & w_{K}=F_{L K}>0, w_{L}=F_{L L}<0 \\
r(K, L)=F_{K}(K, L) & r_{K}=F_{K K}<0, r_{L}=F_{K L}>0
\end{array}
$$

\subsection{Heterogeneous consumers}

We assume a constant population of mass $N$. Individual $i$ owns $K_{i}(t)$ units of capital at time $t$, so that the total amount of capital in the economy at time $t$ is

$$
K^{T}(t)=\int_{0}^{N} K_{i}(t) d i
$$

and the average per capita amount of capital is

$$
K(t)=\frac{1}{N} \int_{0}^{N} K_{i}(t) d i
$$

We define the relative share of capital owned by agent $i$ to be

$$
k_{i}(t)=\frac{K_{i}(t)}{K(t)}
$$

the mean of which is 1 , and the initial (given) standard deviation of which is $\sigma_{k, 0}$.

Each individual is endowed with a unit of time that can be allocated either to leisure, $l_{i}$, or to work, $1-l_{i} \equiv L_{i}$. The agent maximizes lifetime utility, assumed to be a function of consumption, the amount of leisure time, and government expenditure, $G$ (taken as given), in accordance with the isoelastic utility function 


$$
\max \int_{0}^{\infty} \frac{1}{\gamma}\left(C_{i}(t) l_{i}^{\eta} G^{\theta}\right)^{\gamma} e^{-\beta t} d t, \quad \text { with }-\infty<\gamma<1, \eta>0,1>\gamma(1+\eta)
$$

where $1 /(1-\gamma)$ equals the intertemporal elasticity of substitution. The preponderance of empirical evidence suggests that this is relatively small, certainly well below unity, so that we shall restrict $\gamma<0 .^{8}$ The parameter $\eta$ represents the elasticity of leisure in utility, while $\theta$ measures the relative importance of public consumption in private utility. This maximization is subject to the agent's capital accumulation constraint

$$
\dot{K}_{i}(t)=\left[\left(1-\tau_{k}\right) r(t)-\delta\right] K_{i}(t)+\left(1-\tau_{w}\right) w(t)\left(1-l_{i}(t)\right)-\left(1+\tau_{c}\right) C_{i}(t)+T_{i}
$$

where $\tau_{k}, \tau_{w}, \tau_{c}$ and $T_{i}$ are, respectively, the tax rates on capital income, labor income, consumption, and lump-sum transfers that the agent takes as exogenously given. The agent's optimality conditions [reported in the Appendix] imply

$$
\begin{gathered}
\eta \frac{C_{i}}{l_{i}}=w(K, L)\left(\frac{1-\tau_{w}}{1+\tau_{c}}\right) \\
(\gamma-1) \frac{\dot{C}_{i}}{C_{i}}+\eta \gamma \frac{\dot{l}_{i}}{l_{i}}=\frac{\dot{\lambda}_{i}}{\lambda_{i}}=\beta+\delta-r(K, L)\left(1-\tau_{k}\right)
\end{gathered}
$$

where $\lambda_{i}$ is agent $i$ 's shadow value of capital. Equation (5) equates the marginal rate of substitution between consumption and leisure to the [after-tax] price of leisure, while (6) is the Euler equation modified to take into account the fact that leisure changes over time. The important point about (6) is that each agent, irrespective of capital endowment, chooses the same growth rate for the shadow value of capital. Using (5) we may write the individual's accumulation equation, (4), in the form

$$
\frac{\dot{K}_{i}}{K_{i}}=r(K, L)\left(1-\tau_{k}\right)-\delta+\frac{w(K, L)\left(1-\tau_{w}\right)}{K_{i}}\left(1-l_{i} \frac{1+\eta}{\eta}\right)-\frac{T_{i}}{K_{i}}
$$

\subsection{Government}

We assume that the government sets its expenditure and transfers as fractions of aggregate

\footnotetext{
${ }^{8}$ See, for example, the discussion of the empirical evidence summarized and reconciled by Guvenen (2006).
} 
output, in accordance with $G=g Y(t), T=\tau Y(t)$, so that $g$ and $\tau$ become the policy variables along with the tax rates. We also assume that it maintains a balanced budget expressed as

$$
\tau_{k} r(K, L) K+\tau_{w} w(K, L)(1-l)+\tau_{c} C=G+T=(g+\tau) F(K, L)
$$

This means that, if $\tau_{w}, \tau_{k}, \tau_{c}$, and $g$ are fixed, as we shall assume, then along the transitional path, as economic activity and the tax/expenditure base is changing, the rate of lump-sum transfers must be continuously adjusted to maintain budget balance. ${ }^{9}$ In order to abstract from any direct distribution effects arising from lump-sum transfers (which are arbitrary), we shall assume

$$
\frac{T_{i}(t)}{T(t)}=\frac{K_{i}(t)}{K(t)}
$$

which ensures that

$$
\int_{0}^{N} T_{i} d i=\frac{T}{K} \int_{0}^{N} K_{i} d i=T
$$

consistent with the government budget constraint. ${ }^{10}$

\subsection{Derivation of the macroeconomic equilibrium}

In general, we shall define economy-wide averages as

$$
Z(t)=\frac{1}{N} \int_{0}^{N} Z_{i}(t) d i
$$

Summing over agents, equilibrium in the capital and labor markets is described by

$$
\begin{aligned}
& K=\frac{1}{N} \int_{0}^{N} K_{i}(t) d i \\
& L=1-l=\frac{1}{N} \int_{0}^{N}\left(1-l_{i}(t)\right) d i
\end{aligned}
$$

\footnotetext{
${ }^{9}$ In our simulations we take $\tau>0$; $\tau<0$ therefore corresponds to a rate of lump-sum taxation.

${ }^{10}$ Like all lump-sum transfer schemes, we assume that individual agents are unaware of the rule adopted by the government. An alternative procedure would be to introduce debt financing along the transitional path, but given perfect markets, Ricardian Equivalence implies that this is essentially equivalent to what we are doing. The one difference is that the relative capital stock discussed in Section 3.1 is replaced by relative wealth (capital plus government bonds). But results are essentially identical to those we obtain.
} 
Equation (9b) gives the relationship between average leisure and the average labor supply. Note that in equations (2) we have defined the wage and the interest rate, $w, r$, and expressed them as functions of average employment, $L$. From (9b), we can equally well write them as functions of aggregate leisure time, $(1-l)$, namely, $w=w(K, l)$ and $r=r(K, l)$.

Taking the time derivative of (5) and using (6) we can show (see Appendix)

$$
\frac{\dot{C}_{i}}{C_{i}}=\frac{\dot{C}}{C} ; \quad \frac{\dot{l}_{i}}{l_{i}}=\frac{i}{l} \quad \text { for all } i
$$

That is, all agents will choose the same growth rate for consumption and leisure, implying further that average consumption, $C$, and leisure, $l$, will also grow at the same common growth rates.

Now turn to the aggregates. Summing (5) and (7) over all agents, the aggregate economywide consumption-leisure ratio and capital accumulation equations are given by

$$
\begin{gathered}
\eta \frac{C}{l}=w(K, l)\left(\frac{1-\tau_{w}}{1+\tau_{c}}\right) \\
\frac{\dot{K}}{K}=r(K, l)\left(1-\tau_{k}\right)-\delta+\frac{w(K, l)\left(1-\tau_{w}\right)}{K}\left(1-l \frac{1+\eta}{\eta}\right)-\frac{T}{K}
\end{gathered}
$$

Let $\tau_{l} \equiv\left(\tau_{w}+\tau_{c}\right) /\left(1+\tau_{c}\right)$ be the effective tax rate on labor. We can then express the consumptionleisure ratio as $\eta C / l=w\left(1-\tau_{l}\right)$, which implies that $\tau_{l}$ is a crucial determinant of the allocation of time, as in Prescott (2004).

Summing over (6) and using (5'), (7') and the definitions of $r$ and $w$ we can express the macroeconomic equilibrium by the pair of dynamic equations (see Appendix)

$$
\begin{gathered}
\dot{K}=(1-g) F(K, L)-\frac{F_{L}(K, L) l}{\eta}\left(\frac{1-\tau_{w}}{1+\tau_{c}}\right)-\delta K \\
i=\frac{F_{K}\left(1-\tau_{k}\right)-(\beta+\delta)-\left[(1-\gamma) \frac{F_{K L}}{F_{L}}-\theta \gamma \frac{F_{K}}{F}\right]\left[(1-g) F(K, L)-\frac{F_{L}(K, L) l}{\eta}\left(\frac{1-\tau_{w}}{1+\tau_{c}}\right)-\delta K\right]}{\frac{1-\gamma(1+\eta)}{l}-\left[(1-\gamma) \frac{F_{L L}}{F_{L}}-\theta \gamma \frac{F_{L}}{F}\right]}(11)
\end{gathered}
$$

The important observation about this pair of equations is its implication that aggregate behavior is 
independent of income and wealth distribution

\section{$2.4 \quad$ Steady state}

Assuming that the economy is stable, the aggregate dynamic system described by (11) converges to a steady state characterized by a constant average capital stock, labor supply, and leisure time, denoted by $\tilde{K}, \tilde{L}$ and $\tilde{l}$, respectively. Setting $\dot{K}=\dot{l}=0$, the steady state is summarized by

$$
\begin{aligned}
& \left(1-\tau_{k}\right) F_{K}(\tilde{K}, \tilde{L})=\beta+\delta \\
& (1-g) F(\tilde{K}, \tilde{L})-\frac{F_{L}(\tilde{K}, \tilde{L}) \tilde{l}}{\eta}\left(\frac{1-\tau_{w}}{1+\tau_{c}}\right)-\delta \tilde{K}=0 \\
& \tilde{L}+\tilde{l}=1
\end{aligned}
$$

Note that (12b) implies

$$
(1-g) \tilde{F}-\delta \tilde{K}-\tilde{F}_{L} \tilde{L}\left(1-\tau_{l}\right)+F_{L}\left(1-\tau_{l}\right)[1-\tilde{l}-\tilde{l} / \eta]=0 .
$$

If we assume that the share of private consumption expenditure, $[(1-g)-\delta(\tilde{K} / \tilde{F})]$, exceeds the after-tax share of labor income, $\left(\tilde{F}_{L} \tilde{L} / \tilde{F}\right)\left(1-\tau_{l}\right)$, then (13) imposes the restriction ${ }^{11}$

$$
\tilde{l}>\frac{\eta}{1+\eta}
$$

This inequality yields a lower bound on the steady-state time allocation to leisure that is consistent with a feasible equilibrium. As we will see below, this condition plays a critical role in characterizing the dynamics of the wealth distribution.

In order to describe the dynamics of the distribution of capital and income, we first need to obtain the dynamics of the aggregate magnitudes. Linearizing equations (11a) and (11b) around steady state yields the local dynamics for $K$ and $l$,

\footnotetext{
${ }^{11}$ This condition is likely to be met. For example in our simulations $(1-g)-\delta(\tilde{K} / \tilde{F})=0.69$ and clearly exceeds $\left(\tilde{F}_{L} \tilde{L} / \tilde{F}\right)\left(1-\tau_{l}\right)=0.46$.
} 


$$
\left(\begin{array}{c}
\dot{K} \\
\dot{l}
\end{array}\right)=\left(\begin{array}{ll}
a_{11} & a_{12} \\
a_{21} & a_{22}
\end{array}\right)\left(\begin{array}{c}
K-\tilde{K} \\
l-\tilde{l}
\end{array}\right)
$$

where $a_{11}, a_{12}, a_{21}$ and $a_{22}$ are defined in the Appendix. There we show that, under the assumption that $\theta$ is not too large, $a_{11} a_{22}-a_{12} a_{21}<0$, implying that the steady state is a saddle point. The stable paths for $K$ and $l$ can be expressed as

$$
\begin{aligned}
& K(t)=\tilde{K}+\left(K_{0}-\tilde{K}\right) e^{\mu t} \\
& l(t)=\tilde{l}+\frac{a_{21}}{\mu-a_{22}}(K(t)-\tilde{K})=\tilde{l}+\frac{\mu-a_{11}}{a_{12}}(K(t)-\tilde{K})
\end{aligned}
$$

where $\mu<0$ is the stable eigenvalue. From the sign pattern established in the Appendix, $\left(a_{22}-\mu\right)>0$, implying that the slope of the stable arm depends inversely upon the sign of $a_{21}$. The sign of this expression reflects two offsetting influences of capital on the evolution of leisure. On the one hand, an increase in capital lowers the return to capital and hence the return to consumption, thereby reducing the growth rate of consumption and raising the desire to increase leisure. At the same time, the higher capital stock, by reducing the productivity of labor, raises the benefits from increasing labor, thus reducing the growth of leisure. As we show in the Appendix, which effect dominates depends upon the underlying parameters and in particular upon the elasticity of substitution in production, $\varepsilon$. There we demonstrate that for plausible cases [including the conventional case of Cobb-Douglas production and logarithmic utility $(\varepsilon=1, \gamma=0)] a_{21}<0$, in which case the stable locus is positively sloped; accumulating capital is therefore associated with increasing leisure.

As we will see below, the evolution of average leisure over time is an essential determinant of the time paths of wealth and income inequality. For expositional convenience we shall restrict ourselves to what we view as the more plausible case of a positive sloped stable locus, (16b). Since this relationship holds at all times, we have

$$
l(0)-\tilde{l}=\frac{a_{21}}{\mu-a_{22}}\left(K_{0}-\tilde{K}\right)
$$

Thus consider a situation in which the economy is subject to a policy shock that results in an 
increase in the steady-state average per capita capital stock relative to its initial level $\left(K_{0}<\tilde{K}\right)$. The shock will lead to an initial jump in average leisure, such that $l(0)<\tilde{l}$, so that, thereafter, leisure will increase monotonically during the transition; an analogous relationship applies if $K_{0}>\tilde{K}$. We should point out, however, that in our simulations the net impact of the two offsetting influences of the accumulating capital stock on the transition of leisure [as measured by the slope of (16b)] is small. Consequently the response of leisure following the fiscal shock is completed almost immediately.

\section{The distribution of income and wealth}

\subsection{The dynamics of the relative capital stock}

To derive the dynamics of individual i's relative capital stock, $k_{i}(t) \equiv K_{i}(t) / K(t)$, we combine (7) and (7'). With transfers set such that $T_{i} / K_{i}=T / K$ this leads to

$$
\dot{k_{i}}(t)=\frac{w(K, l)\left(1-\tau_{w}\right)}{K}\left[1-\rho_{i} l\left(1+\frac{1}{\eta}\right)-\left(1-l\left(1+\frac{1}{\eta}\right)\right) k_{i}(t)\right]
$$

where $K, l$ evolve in accordance with $(16 \mathrm{a}, 16 \mathrm{~b})$ and the initial relative capital $k_{i, 0}$ is given from the initial endowment. Since $i_{i} / l_{i}=i / l$ we may write

$$
l_{i}=\rho_{i} l \quad \text { where } \quad \frac{1}{N} \int_{0}^{N} \rho_{i} d i=1
$$

and $\rho_{i}$ is constant for each $i$, and yet to be determined.

To solve for the time path of the relative capital stock, we first note that agent i's steady-state share of capital satisfies

$$
1-\rho_{i} \tilde{l}\left(1+\frac{1}{\eta}\right)-\left(1-\tilde{l}\left(1+\frac{1}{\eta}\right)\right) \tilde{k}_{i}=0 \quad \text { for each } i
$$

or, equivalently

$$
\left(\rho_{i}-1\right) \tilde{l}=\tilde{l_{i}}-\tilde{l}=\left(\tilde{l}-\frac{\eta}{1+\eta}\right)\left(\tilde{k}_{i}-1\right) \quad \text { for each } i
$$


Recalling (14), this equation implies that the higher an agent's steady-state relative capital stock (wealth), the more leisure he chooses and the less labor he supplies. This relationship is a critical determinant of the distributions of wealth and income and explains why the evolution of the aggregate quantities such as $K$ and $l$ are unaffected by distributional aspects. There are two key factors contributing to this: (i) the linearity of the agent's labor supply as a function of his relative capital, and (ii) the fact that the sensitivity of labor supply to relative capital is common to all agents, and depends upon the aggregate economy-wide leisure. As a consequence, aggregate labor supply depends only on the aggregate amount of capital but not on its distribution amongst agents.

To analyze the evolution of the relative capital stock, we linearize equation (17) around the steady-state $\tilde{K}, \tilde{l}, \tilde{k}_{i}, \tilde{l}_{i}$, determined by (12) and (18'). From (14), the coefficient in (17) on $k_{i}>0$, implying that in order for agent $i$ 's relative stock of capital to converge to a finite quantity, and therefore yield a finite steady-state wealth distribution, $k_{i}(t)$ must follow the stable path: ${ }^{12}$

$$
k_{i}(t)-1=\delta(t)\left(\tilde{k}_{i}-1\right)
$$

where

$$
\delta(t) \equiv 1+\frac{\frac{F_{L}(\tilde{K}, \tilde{l})\left(1-\tau_{w}\right)}{\tilde{K}}\left[1-\frac{l(t)}{\tilde{l}}\right]}{\frac{F_{L}(\tilde{K}, \tilde{l})\left(1-\tau_{w}\right)}{\tilde{K}}\left[\tilde{l}\left(\frac{1+\eta}{\eta}\right)-1\right]-\mu},
$$

Setting $t=0$ in (19) and (20), we obtain

$$
k_{i, 0}-1=\delta(0)\left(\tilde{k}_{i}-1\right)=\left(1+\frac{\frac{F_{L}(\tilde{K}, \tilde{l})\left(1-\tau_{w}\right)}{\tilde{K}}\left[1-\frac{l(0)}{\tilde{l}}\right]}{\frac{F_{L}(\tilde{K}, \tilde{l})\left(1-\tau_{w}\right)}{\tilde{K}}\left[\tilde{l}\left(\frac{1+\eta}{\eta}\right)-1\right]-\mu}\right)\left(\tilde{k}_{i}-1\right)
$$

where $k_{i, 0}$ is given from the initial distribution of capital endowments.

The evolution of agent $i$ 's relative capital stock is determined as follows. First, given the

\footnotetext{
${ }^{12}$ The formal structure of the relative dynamics is similar to that of Turnovsky and García-Peñalosa (2008), where the details are spelled out in greater detail.
} 
time path of the aggregate economy, and the distribution of initial capital endowments, (21) determines the steady-state distribution of capital, $\left(\tilde{k}_{i}-1\right)$, which together with (19) then yields the entire time path for the distribution of capital. Using (19) - (21), and equations (16), describing the evolution of the aggregate economy, we can express the time path for $k_{i}(t)$ in the form

$$
k_{i}(t)-\tilde{k}_{i}=\left(\frac{\delta(t)-1}{\delta(0)-1}\right)\left(k_{i, 0}-\tilde{k}_{i}\right)=\left(\frac{l(t)-\tilde{l}}{l(0)-\tilde{l}}\right)\left(k_{i, 0}-\tilde{k}_{i}\right)=e^{\mu t}\left(k_{i, 0}-\tilde{k}_{i}\right)
$$

from which we see that $k_{i}(t)$ also converges to its steady state value at the rate $\mu$.

Because of the linearity of (19), (21), and (22), we can immediately transform these equations into corresponding relationships for the standard deviation of the distribution of capital, which serves as a convenient measure of wealth inequality. Specifically, corresponding to these three equations we obtain

$$
\begin{aligned}
& \sigma_{k}(t)=\delta(t) \tilde{\sigma}_{k} \\
& \sigma_{k, 0}=\delta(0) \tilde{\sigma}_{k} \\
& \sigma_{k}(t)-\tilde{\sigma}_{k}=e^{\mu t}\left(\sigma_{k, 0}-\tilde{\sigma}_{k}\right)
\end{aligned}
$$

The allocation of wealth then converges to a long-run distribution. Moreover, it follows from (22) that the ranking of agents according to wealth remains unchanged throughout the transition.

By combining equations (19') and (21') together with the definition of $\delta(t)$ given in (20) we can readily characterize the evolution of the wealth distribution in terms of the evolution of average leisure, namely,

$$
\sigma_{k, 0}>\sigma_{k}(t)>\tilde{\sigma}_{k} \text { if and only if } l(0)<l(t)<\tilde{l}
$$

That is, wealth inequality will decrease (increase) according to whether leisure increases (decreases) along the transitional path. Moreover, since average leisure increases with the accumulation of capital, in accordance with (16b), we see further that

$$
\sigma_{k, 0}>\sigma_{k}(t)>\tilde{\sigma}_{k} \text { if and only if } K_{0}<K(t)<\tilde{K}
$$


Thus we conclude that if the economy undergoes an expansion (contraction) in its capital stock then wealth inequality will decrease (increase) during the transition, and the long-run distribution of wealth will be less (more) unequal than is the initial distribution.

The intuition for this result can be easily seen by noting from (19) and (20), that

$$
\operatorname{sgn}\left(\tilde{k}_{i}-k_{i, 0}\right)=\operatorname{sgn}\left(\tilde{k}_{i}-1\right)(l(0)-\tilde{l})
$$

Recall that if the economy converges to the steady state from below, then $l(0)<\tilde{l}$. Then for people who end up above the mean level of wealth, their relative wealth will have decreased during the transition $\tilde{k}_{i}<k_{i, 0}$, while for people who end up below the mean level of wealth, their relative wealth will have increased, $\tilde{k}_{i}>k_{i, 0}$, implying a narrowing of the wealth distribution. Equations (20) and (21) further imply that the closer $l(0)$ jumps to its steady state, $\tilde{l}$, the smaller the subsequent adjustment in $l(t)$, and hence the smaller is the overall change in the distribution of wealth. This is because if the economy and therefore all individuals fully adjust their respective leisure times instantaneously, they will all accumulate wealth at the same rate, causing the wealth distribution to remain unchanged.

\subsection{Before-tax income distribution}

We define the income of individual $i$ at time $t$ as $Y_{i}(t)=r(t) K_{i}(t)+w(t)\left(1-l_{i}(t)\right)$, average economy-wide income as $Y(t)=r(t) K(t)+w(t)(1-l(t))$, and we are interested in the evolution of relative income, defined as $y_{i}(t) \equiv Y_{i}(t) / Y(t)$. Letting $s(t) \equiv F_{K} K / Y$ denote the share of output earned by capital, and recalling that $l_{i}=\rho_{i} l$, the relative income of agent $i$ may be expressed as

$$
y_{i}(t)-1=s(t)\left(k_{i}(t)-1\right)+(1-s(t)) \frac{l(t)}{1-l(t)}\left(1-\rho_{i}\right)
$$

This measure has two components, relative capital income, described by the first term in (24), and relative labor income, reflected in the second term. The capital share determines the relative contribution of capital and labor to overall income, for given individual endowments. Using equation (18) to substitute for $\rho_{i}$ and (19), we may write (24) in the form 


$$
y_{i}(t)-1=\varphi(t)\left(k_{i}(t)-1\right)
$$

where

$$
\varphi(t) \equiv s(t)-(1-s(t)) \frac{l(t)}{1-l(t)}\left(1-\frac{1}{\tilde{l}} \frac{\eta}{1+\eta}\right) \frac{1}{\delta(t)} .
$$

Again, because of the linearity of (25) in $k_{i}(t)$ we can express the relationship between relative income and relative capital (wealth) in terms of corresponding standard deviations of their respective distributions, namely

$$
\sigma_{y}(t)=\varphi(t) \sigma_{k}(t)
$$

If labor is supplied inelastically, $\varphi(t)=s(t)$ so that $\sigma_{y}(t) / \sigma_{k}(t)=s(t)$. However, when labor is flexible, poor agents supply more labor than do the wealthy, which partially offsets the effect of the unequal distribution of capital. From inequality (14) the term in square brackets in equation (26) is positive and hence $\varphi(t)<s(t)$, implying that the ratio of wealth inequality to income inequality is less than the share of capital.

Letting $t \rightarrow \infty$, we can express the steady-state distribution of income as

$$
\tilde{\sigma}_{y}=\tilde{\varphi} \tilde{\sigma}_{k}
$$

where

$$
\tilde{\varphi}=\lim _{t \rightarrow \infty} \varphi(t)=1-\frac{1}{1+\eta} \frac{1-\tilde{s}}{1-\tilde{l}}=1-\frac{1}{1+\eta} \frac{F_{L}(\tilde{K}, \tilde{L})}{F(\tilde{K}, \tilde{L})}
$$

From (26') we can compare the long-run distribution of income to the initial one, namely

$$
\frac{\tilde{\sigma}_{y}}{\sigma_{y, 0}}=\frac{\tilde{\varphi}}{\varphi_{0}} \frac{\tilde{\sigma}_{k}}{\sigma_{k, 0}}=1-\frac{1+\eta-(1-\tilde{s}) /(1-\tilde{l})}{1+\eta-(1-s(0)) /(1-l(0))} \frac{\tilde{\sigma}_{k}}{\sigma_{k, 0}}
$$

where the subscript 0 identifies the initial distribution, from which we infer that in general $\operatorname{sgn}\left(\tilde{y}_{i}-1\right)=\operatorname{sgn}\left(y_{i, 0}-1\right)$. The distribution of income hence converges to a long-run distribution such that the relative ranking of agents according to income is the same as that of capital, as well as that of the initial income distribution. Whether the long-run distribution is more or less unequal than 
the initial distribution depends on the long-run change in the distribution of capital, as reflected in $\tilde{\sigma}_{k} / \sigma_{k, 0}$, and factor returns, as reflected in $\tilde{\varphi} / \tilde{\varphi}_{0}$.

These dynamics of income distribution can be understood most conveniently by substituting (21') and (26) into (25), rewriting it as

$$
\sigma_{y}(t)=s(t) \sigma_{k}(t)-[1-s(t)] \frac{l(t)}{1-l(t)}\left[1-\frac{1}{\tilde{l}} \frac{\eta}{1+\eta}\right] \tilde{\sigma}_{k}
$$

The first point to observe is that although the distribution of wealth, $\sigma_{k}(t)$ evolves gradually, the initial jump in leisure, $l(0)$, which impacts on $\sigma_{y}(0)$ both directly and indirectly through $s(0)$, means that income distribution is subject to an initial jump following a structural or policy shock. Thereafter, it evolves continuously in response to the evolution of the distribution of capital and factor returns. Taking the time derivative of (28) we see further that

$$
\dot{\sigma}_{y}(t)=s(t) \dot{\sigma}_{k}(t)-\frac{(1-s(t)}{(1-l(t))^{2}}\left[1-\frac{1}{\tilde{l}} \frac{\eta}{1+\eta}\right] \tilde{\sigma}_{k} \dot{l}(t)+\left(\sigma_{k}(t)+\frac{l}{1-l(t)}\left[1-\frac{1}{\tilde{l}} \frac{\eta}{1+\eta}\right] \tilde{\sigma}_{k}\right) \dot{s}(t)
$$

This equation indicates how the evolution of relative income depends upon two factors, the evolution of relative capital income, reflected in the first term in (28), and that of relative labor income. The latter can be expressed as a function of the evolution of aggregate leisure (i.e. labor supply), and of the relative rewards to capital and labor, as reflected by the capital share, $s(t)$.

It is useful to begin by considering a Cobb-Douglas production function. In this case the capital share remains constant, and whether income inequality increases or decreases over time depends on whether the economy is responding to an expansion or contraction. Suppose the economy is undergoing an expansion so that $K_{0}<\tilde{K}$. Then $l(0)<\tilde{l}$ and average leisure is rising during the transition, $i(t)>0$, so that wealth inequality is decreasing; see (23). In addition, the fact that average leisure is rising means that agents having above average wealth, increase leisure more, causing a decline in their relative income during the transition. The opposite would be true for an agent with below-average wealth, and hence income inequality [the second term in (28')] will decline during the transition to the steady state. For an economy that is experiencing a contraction, $K_{0}>\tilde{K}$, then $l(0)>\tilde{l}$, and together with the fact that wealth inequality is increasing, income 
inequality will rise during the transition.

The evolution of factor shares may reinforce or offset these effects, depending upon the elasticity of substitution in production. In general, we can easily establish that $\operatorname{sgn}(\dot{s})=\operatorname{sgn}\left[(\varepsilon-1)\left(\tilde{K}-K_{0}\right)\right]$. Thus, for an economy experiencing an expansion, if $\varepsilon<1$, its declining capital share will reinforce the first two effects and income inequality will decline unambiguously. If $\varepsilon>1$, then $\dot{s}(t)>0$ and this effect is offsetting and if dominant would cause income inequality to increase over time.

\subsection{After-tax income inequality}

An important aspect of income taxes is their direct redistributive effect, causing us to distinguish between before-tax and after-tax income distributions, with the latter measure being arguably of greater significance. We thus define agent $i$ 's after-tax (net) relative income as

$$
y_{i}^{a}=\frac{r K_{i}\left(1-\tau_{k}\right)+w\left(1-l_{i}\right)\left(1-\tau_{w}\right)}{r K\left(1-\tau_{k}\right)+w(1-l)\left(1-\tau_{w}\right)}
$$

Note that this measure ignores the direct distributional impacts of lump-sun transfers, which are arbitrary. Recalling the expression for before-tax relative income and the definition of $\varphi$, we can express this as

$$
y_{i}^{a}(t)-1=\psi(t)\left(k_{i}(t)-1\right)
$$

where

$$
\psi(t) \equiv \varphi(t)+\frac{s(t)\left(\tau_{w}-\tau_{k}\right)}{s(t)\left(1-\tau_{k}\right)+(1-s(t))\left(1-\tau_{w}\right)}(1-\varphi(t))
$$

and $\varphi(t)$ is defined in (26). Thus we see that both income tax rates, $\tau_{k}$ and $\tau_{w}$, exert two effects on the after-tax income distribution. First, by influencing $\varphi(t)$, they influence gross factor returns, and therefore the before-tax distribution of income. But in addition, they have direct redistributive effects, which are captured by the second term on the right hand side of (31). Post-tax income inequality will be less than pre-tax income inequality if and only if $\tau_{w}<\tau_{k}$. In contrast, the 
consumption tax has no redistributive effect.

Again, we can express post-tax income inequality as

$$
\sigma_{y}^{a}(t)=\psi(t) \sigma_{k}(t)
$$

which asymptotically becomes

$$
\tilde{\sigma}_{y}^{a}=\tilde{\psi} \tilde{\sigma}_{k},
$$

where

$$
\tilde{\psi} \equiv \tilde{\varphi}+\frac{\tilde{s}\left(\tau_{w}-\tau_{k}\right)}{\tilde{s}\left(1-\tau_{k}\right)+(1-\tilde{s})\left(1-\tau_{w}\right)}(1-\tilde{\varphi}) .
$$

\section{Steady state effects of fiscal policy}

Our objective is to examine the effect of different fiscal policies on the time paths of the distributions of wealth and income. We begin by considering the steady-state effects, since with forward looking agents, these long-run responses are critical in determining the transitional dynamics. We conduct two exercises, summarized in Tables 1 and 2. First we examine uncompensated fiscal changes, meaning that the change is financed by a reduction in transfers (or equivalently by lump-sum taxes). Then we compare alternative modes of financing a specified increase in government spending.

\subsection{Uncompensated fiscal policy}

Since distribution is determined by aggregate behavior, we begin with the former, which are summarized in the first four rows of Table 1 . These results are standard and require little discussion. There it is seen that an increase in government spending raises the long-run capital stock, labor supply, and therefore output, proportionately, leaving factor shares unaffected. In contrast, an increase in the tax on capital income raises the long-run marginal physical product of capital, implying that it reduces the capital-labor ratio. Although capital declines unambiguously, labor will 
do so only if the elasticity of substitution in production, $\varepsilon$, is sufficiently large. ${ }^{13}$ While output also declines unambiguously, the net effect on the factor shares depends upon $(\varepsilon-1){ }^{14}$

Having established the effect on aggregate magnitudes, we can turn to the distributional impacts, reported in Rows 5-7. Noting the response of capital, reported in Row 1, in conjunction with (23'), we immediately conclude that an increase in government expenditure reduces long-run wealth inequality, $\tilde{\sigma}_{k}$. In contrast, an increase in any of the three taxes, by reducing the long-run capital stock, results in an increase in wealth inequality.

As discussed in Section 3, pre-tax income inequality is given by $\tilde{\sigma}_{y}=\tilde{\varphi} \tilde{\sigma} \tilde{\sigma}_{k}$, the response of which depends upon that of both $\tilde{\sigma}_{k}$ and $\tilde{\varphi}$, reported in Row 6. There we see that an increase in $g$ raises $\tilde{\varphi}$, while an increase in either $\tau_{c}$ or $\tau_{w}$ reduces $\tilde{\varphi}$, in all cases having an offsetting effect on pre-tax income inequality from that due to wealth accumulation.

Consider, for example, the effect of increasing government expenditure. On the one hand, during the transition to the new steady state the distribution of wealth will become less dispersed, tending to reduce income inequality, as noted. At the same time, recalling that

$$
\tilde{\varphi}=1-\frac{1}{1+\eta} \frac{1-\tilde{s}}{1-\tilde{l}}
$$

we see that with factor shares, $\tilde{s}$, remaining unchanged (see Row 4) and with the expansion in government expenditure leading to an increase in labor supply (lower $\tilde{l}$ ), this causes an increase in $\tilde{\varphi}$. The increase in $\tilde{\varphi}$ tends to raise income inequality, and offsets the impact of a less dispersed distribution of capital.

To understand the effect of labor supply on inequality, we rewrite (18') in the form

$$
\tilde{L}_{i}=\tilde{L}-\left(\tilde{l}-\frac{\eta}{1+\eta}\right)\left(\tilde{k}_{i}-1\right)
$$

which implies that individual labor supplies are negatively correlated with capital endowments and have a standard deviation of $\tilde{\sigma}_{L}=(\tilde{l}-\eta /(1+\eta)) \tilde{\sigma}_{k}$. An increase in labor supply, that is, a decline in

\footnotetext{
${ }^{13}$ For example, $\varepsilon>\tilde{s}$ is a weak condition to ensure that employment declines.

${ }^{14}$ This is not surprising since $\tau_{k}$ is equivalent to a decline in productivity, the effect of which on factor shares is well known to depend upon $(\varepsilon-1)$.
} 
$\tilde{l}$, implies less dispersion of labor incomes which, since they are negatively correlated with capital endowments, tends to increase income inequality.

The effects of increases in the consumption and wage tax are opposite to that of government expenditure, and can be explained by the same intuition. However, the impact of $\tau_{k}$ on $\tilde{\varphi}$ is more complex since there are now three effects in operation. First, during the transition to the new steady state with a lower stock of capital the distribution of wealth will become more dispersed. Second, $\tilde{\varphi}$ falls as the new steady state generates a lower $\tilde{l}$. Third, the reduction in the capital-labor ratio implies a change in the capital share, $\widetilde{s}$, the impact of which depends on whether $\varepsilon_{<}^{>} 1$. In the case of the Cobb-Douglas production function this effect is zero and since in this case $\partial \tilde{L} / \partial \tau_{k}<0$, then $\tilde{\varphi}$ also falls.

Turning to after-tax income inequality, we see from (31) that neither $g$ nor $\tau_{c}$ have direct redistributive effects, implying that their respective impacts on $\tilde{\psi}$ operate entirely through $\tilde{\varphi}$. To the extent that $\tau_{w} \neq \tau_{k}$, the differential between them will induce an indirect redistributive effect, though this vanishes if these two tax rates are equal. In this case changes in $g$ or $\tau_{c}$ have identical effects on the pre-tax and post-tax income distributions. A higher tax on labor makes the fiscal system less progressive, the reason being that labor income is less unequally distributed than is capital income. Together with the fact that $\partial \tilde{\varphi} / \partial \tau_{w}<0$, this implies that the overall effect of $\tau_{w}$ on post-tax inequality is ambiguous. While in principle the direct impact of a higher tax on capital income is ambiguous, if $\varepsilon \leq 1$ it is clearly negative, independent of the tax rates, $\tau_{w}, \tau_{k}$. For the Cobb-Douglas case this reinforces the pre-tax income inequality effect and post-tax income inequality falls relative to wealth inequality.

\subsection{Compensated increases in government expenditure}

We now consider the impact of an increase in government expenditure financed, alternatively, through increases in the lump-sum tax (decrease in transfers), consumption tax, labor income tax, and capital income tax. These are summarized in Table 2.

In all cases we assume that the economy starts from an initial equilibrium in which the government expenditure is fully financed by lump-sum transfers, so that $g_{0}+\tau_{0}=0$ in equation (8), and initial distortionary tax rates are all zero, i.e. $\tau_{c}=\tau_{w}=\tau_{k}=0$ in the initial equilibrium. The 
change in taxes required by the increase in government expenditure is given by the government budget constraint (8), which we can write in the form

$$
\tau_{k} s+\tau_{w}(1-s)+\tau_{c} C / F=g+\tau
$$

With $\tau_{c}=\tau_{w}=\tau_{k}=0$ the effects of a lump-sum tax financed increase in government expenditure, initially reported in Table 1 , now simplify to the expressions reported in the first column of Table 2. In particular, the effects on pre-tax and post-tax income inequality are identical. In either case, a one percentage point increase in government spending leads to a less than proportionate increase in income inequality.

In the case of distortionary tax financing, we assume that the corresponding tax rate is set such that it fully finances the long-run change in government expenditure. Thus starting from $\tau_{c}=\tau_{w}=\tau_{k}=0$, the corresponding required changes in the three tax rates are respectively

$$
d \tau_{c}=(\tilde{F} / \tilde{C}) d g, d \tau_{w}=(1 /(1-\tilde{s})) d g, d \tau_{k}=(1 / \tilde{s}) d g
$$

This means that during the transition residual financing using lump-sum tax financing must also be employed to ensure that the budget remains balanced at all times. ${ }^{15}$ Thus in general, the response of variable $X$, say, to a distortionary tax-financed increase in government expenditure is given by

$$
\begin{array}{ll}
\left.\frac{d X}{d g}\right|_{\tau_{i}}=\frac{\partial X}{\partial g}+\frac{\partial X}{\partial \tau_{i}} \frac{\partial \tau_{i}}{\partial g} & \tau_{i}=\tau_{c}, \tau_{w}, \tau_{k}
\end{array}
$$

Turning first to the case where the increase in government expenditure is financed using a consumption tax, we see from column 2 in Table 2 that the net effects are zero. The direct effects of the expansion are exactly offset by the distortionary tax effects, implying that on balance this mode of financing has no impact on either aggregate quantities or on distribution. This is unsurprising. First, the reduction in consumption due to the higher tax is exactly offset by the higher marginal utility of consumption induced by the increase in $g$, thus leaving capital and labor unchanged.

\footnotetext{
${ }^{15}$ Starting from initial zero distortionary tax rates, (32) implies unique tax rates necessary to finance the increase in government expenditure. In contrast, the simulations begin from non-zero initial distortionary tax rates, raising the potential for the increase in government expenditure to be financed by two different tax rates. While this was not encountered in our simulations, the appropriate way to deal with this issue, in light of the linearized dynamics, would be to consider the one closest to the initial tax rate.
} 
Second, the consumption tax has no direct redistributive implications.

In the case where the increase in government expenditure is financed by a higher tax on wage income the distortionary tax effect dominates the direct expenditure effect. As a consequence aggregate capital, labor and output all fall proportionately so that wealth inequality, $\tilde{\sigma}_{k}$ increases. On the other hand, $\tilde{\varphi}$ also declines, thus offsetting the wealth effect. Similar elements apply to the case where the increase in government expenditure is financed using a tax on capital, with the effect on the factor shares playing an additional role.

\section{Numerical Simulations}

To obtain further insights into the dynamics of wealth and income distribution we simulate the economy in response to various shocks. The simulations are based on the following functional forms and standard parameter values, characterizing the benchmark economy:

$$
\begin{array}{ll}
\text { Production function: } & Y=A K^{\alpha} L^{1-\alpha} \\
\text { Basic parameters: } & A=1.2, \alpha=0.4 \\
& \beta=0.04, \gamma=-1.5, \eta=1.75, \theta=0.3, \delta=0.04 \\
\text { Fiscal parameters: } & \tau_{k}=0.20, \tau_{w}=0.20, \tau_{c}=0.04, g=0.15
\end{array}
$$

Preferences are specified by a constant elasticity utility function, with intertemporal elasticity of substitution $1 /(1-\gamma)=0.4$, while the elasticity of leisure in utility is 1.75 and that with respect to government expenditure 0.3. The production function is of the Cobb-Douglas form, with distributional parameter $\alpha=0.4$, and $A=1.2$ scales the initial level of productivity. The depreciation rate is $4 \%$ per annum.

Our measures of inequality are reported in terms of the standard deviation measures employed in our theoretical discussion, with the initial standard deviation of relative capital being normalized to 1 . We suppose that the economy is initially in steady state and consider the impact of policy changes both on the new steady state distributions and on their transitional dynamics.

\subsection{Financing an increase in government expenditure}

Table 3 reports the effect of an increase in government expenditure from its base rate of $15 \%$ 
of output by 5 percentage points to $20 \%$ of output. The first line reports the benchmark equilibrium for the base parameters. ${ }^{16}$ We see that $72.3 \%$ of time is allocated to leisure, the capital-output ratio is 4.00 , and the implied share of output devoted to transfers is $7.76 \%$.

To consider the distributional implications of the expenditure increase, we define the initial steady-state distributions of pre-tax income and post-tax income (prior to any shock) by the respective quantities:

$$
\begin{aligned}
& \tilde{\sigma}_{y, 0} \equiv \varphi_{0} \sigma_{k, 0}=\left[1-\frac{1-s\left(\tilde{K}_{0}, \tilde{L}_{0}\right)}{1-\tilde{l}_{0}} \frac{1}{1+\eta}\right] \sigma_{k, 0}, \\
& \tilde{\sigma}_{y, 0}^{a} \equiv \psi_{0} \sigma_{k, 0}=1-\left(1-\frac{\tilde{\sigma}_{y, 0}}{\sigma_{k, 0}}\right) \frac{1-\tau_{w}}{\tilde{s}\left(1-\tau_{k}\right)+(1-\tilde{s})\left(1-\tau_{w}\right)}
\end{aligned}
$$

where we normalize the initial given distribution of capital by $\sigma_{k, 0}=1$. Since $\tau_{w}=\tau_{k}$ in the benchmark economy, the fiscal system entails no direct redistribution and the initial equilibrium implies standard deviations of pre-tax and post-tax income distributions of $\tilde{\sigma}_{y, 0}^{a}=\tilde{\sigma}_{y, 0}=0.211$.

The next three rows report the numerical effects of financing an (arbitrary) increase in government expenditure of 5 percentage points by a reduction in transfers (i.e. a lump-sum tax), an increase in the wage income tax, and an increase in the capital income tax, respectively. Lump-sum tax financing entails an increase in output, as government expenditure encourages private consumption, leading to an increase in labor supply and capital stock, while the distortions created by capital or wage income taxes result in reduced output and less capital. These results are qualitatively identical to the theoretical results reported in Table 2.

The effects on distribution of the three modes of financing contrast sharply, again reflecting Table 2. In all cases, the long-run changes in wealth inequality are small, reflecting the fact that most of the adjustment in $L$ occurs instantaneously, and as a result the changes in income distribution are dominated by the relative income effects, $\tilde{\varphi}$ and $\tilde{\psi}$. Thus, while lump-sum taxation results in a small reduction in wealth inequality it leads to substantial increases in both pre-tax and post-tax income inequality of around $19 \%$. However, since the contractionary effect of financing by

\footnotetext{
${ }^{16}$ We also examined different elasticities of substitution, namely 0.75 and 1.25 , and obtained results that were qualitatively the same.
} 
a tax on labor income dominates the expenditure effect, this results in a lower labor supply which reduces pre-tax inequality, by over $10 \%$. At the same time the redistributive effect makes the tax structure more regressive. This effect [measured by $\tilde{s}(1-\tilde{\varphi}) /(1-\tilde{s})=0.593$ ] dominates, and post-tax income inequality rises. The opposite occurs with a capital income tax. The increase in labor supply together with the more than proportionate reduction in the capital stock reduce wages, leading to a more dispersed distribution of pre-tax income. This is nevertheless dominated by the increased progressivity of the tax system, resulting from the redistribution, leading in a reduction in after-tax inequality by around $12.8 \%$.

Fig. 1 plots the time paths of the economy in response to the policy changes. The left-side panels illustrate the aggregate magnitudes, capital, labor and income, while the right-side panels represent the distributions of wealth, pre-tax and post-tax income. Both for the aggregate quantities and the distribution measures, the quantities are measured relative to their initial pre-shock, steadystate values. ${ }^{17}$ Note that while the aggregate capital stock and its distribution evolve continuously from their initial values, labor supply, output, and both measures of income distribution undergo initial jumps, arising from the initial jump in leisure. In fact, the bulk of the adjustment in labor supply occurs through its initial jump, leading to little evolution in wealth inequality, although it is more pronounced in the case of capital income tax financing.

As an example, consider the impact of an increase in $g$ financed by a wage income tax. Three effects are in operation. The first is due to the fact that the economy converges to a smaller capital stock, leading to an increase in wealth inequality, although as just noted this effect is small. The second is the effect on income distribution through the change in work hours. The reduction in the labor supply implies that the distribution of labor incomes becomes more dispersed, and since there is negative correlation between individual capital and labor supply, this tends to reduce income inequality. Because of the initial jump in leisure, this comes into effect immediately and in our simulations is always sufficiently strong to offset the impact of a more unequal distribution of capital and pre-tax income inequality increases. Lastly, because wage income is more equally distributed than is capital income, the direct effect of the tax is to increase post-tax inequality. Since the

\footnotetext{
${ }^{17}$ The paths corresponding to the different quantities are as identified in the third panel of the figure.
} 
increase in the tax rate is large ( $\tau_{w}$ goes from $20 \%$ to almost $29 \%$ ) this effect is strong and results in a more unequal distribution of post-tax income than before the policy change.

Three further aspects stand out from this figure. The first is the sharply contrasting effects of $\tau_{w}$ and $\tau_{k}$ on the pre-tax and post-tax income distributions. Financing the increase in $g$ through a wage tax results in a more equal distribution of pre-tax income, but a more unequal distribution of post tax income. The opposite holds when the capital income tax is used. The second concerns the tradeoffs that exist between increases in output and reductions in income inequality. Whereas lumpsum tax financing of the increase in expenditure raises long-run output by over $5 \%$ it increase inequality by $19 \%$. And while capital income tax financing reduces post-tax inequality by $12.8 \%$, it reduces output by $8.58 \%$. Wage income tax financing is a rather unattractive policy, as it reduces output by $2.8 \%$ and raises post-tax income inequality by over $7 \%$. Third, the primary response of income inequality occurs instantaneously, with relatively little adjustment over time. This reflects (i) the corresponding time path for labor supply, as a result of which there is little change in wealth inequality, and (ii) the Cobb-Douglas production function, consistent with (28'). The smaller initial jump in labor in the case of capital income tax financing implies that inequality is subject to more transitional dynamics. ${ }^{18}$

\subsection{Distributional effects of higher taxes}

Consider now an increase in transfers of 5 percentage points financed through increases in either the wage income tax, the capital income tax, or the consumption tax. The way we have set up the transfers implies that they are distributionally neutral, and the only effect will be due to the impact of higher distortionary taxes. Starting from the same initial steady state, Table 4 reports the responses of both the economy-wide aggregates and the distributions of wealth and income, while Fig. 2 illustrates their dynamics.

All three forms of distortionary taxation result in a decline in capital stock, labor supply and average output. Hence, in all three cases wealth inequality increases, while both pre-tax and post-tax

\footnotetext{
${ }^{18}$ We should note that the qualitative nature of the time paths is somewhat specific to the shocks. Basically, labor adjusts more rapidly to consumption and labor income taxes than it does to a tax on capital income. There are even more pronounced transitional dynamics in distribution in response to a productivity shock; see Turnovsky and García-Peñalosa (2008).
} 
income inequality decline. As discussed earlier, a reduced labor supply implies more dispersion of labor incomes and, since they are negatively correlated with capital endowments, tends to reduce income inequality. The wage income tax generates the largest reduction in pre-tax inequality, but the smallest one in terms of post-tax inequality due to the direct effect of the tax. The consumption tax is clearly preferable to the wage tax, since it entails a smaller output loss (4.8\% instead of $7.8 \%$ ) while the reduction of after-tax income inequality is nearly $50 \%$ larger than that entailed by a higher wage tax. Increasing the capital income tax yields the largest reduction in post-tax income inequality, although at a substantial cost in terms of output (it falls by almost 13\%). Taken together, Figs. 1 and 2 highlight how the consequences of tax increases on income distribution depend critically upon how the resulting revenues are spent.

\subsection{Tax changes in Europe and the United States}

An extensive literature has examined the effect that higher taxation in Europe, especially of wage incomes, has had on the labor supply and on the income gap between the US and the large European economies; see Prescott (2004). This literature has, however, paid little attention to the distributional implications of tax changes. In this section we use our model to assess qualitatively the impact of observed tax changes on the distribution of income.

Carey and Rabesona (2004) report effective tax rates in various OECD countries computed in a systematic way and compare the period 1975-80 to 1990-2000. During that period the US experienced a reduction in the capital income tax of 5 percentage points, from 28 to 23 percent, and an increase in the wage tax of $1 \%$. In Germany the capital tax fell and that on wages rose -by $2 \%$ and 2\%, respectively-, while in France both taxes rose, by 5\% and 7\%, respectively. We obtain the numerical solution to the model using the wage and capital tax rates calculated by Carey and Rabesona for these three countries. We assume that the consumption tax rates remain unchanged, maintaining them at 5\%,13\%, and 15\% for the US, Germany, and France, respectively. Similarly we suppose that the shares of government expenditure in the US, Germany, and France are, respectively, $22 \%$, 32\% and $40 \%$, in both cases roughly in line with existing evidence. The changes 
in taxes are absorbed by (distributionally neutral) changes in the transfer. The values of all policy parameters are reported in Table 3.

We suppose that each of these economies is initially in steady state, and that in each economy the capital and wage income tax rate are changed simultaneously by the indicated amounts. Figure 3 plots the dynamics of both the aggregate magnitudes and of the distributional variables. The tax changes in the US result in an increase in the labor supply, capital stock, and output. The increase in the labor supply leads to less dispersion of labor incomes, which initially increases pretax income inequality, although over time this effect is offset by falling wealth inequality. However, the sharp reduction in the capital income tax has a strong direct redistributive effect that results in a more dispersed distribution of post-tax income, with inequality increasing by about $12 \%$.

In France the increases in the two tax rates result in a sharp decline in output due to both a lower stock of capital and labor supply. The increase in aggregate leisure implies a more dispersed distribution of hours of work, which has a strong equalizing effect, and reduces pre-tax income dispersion by about $25 \%$ and post-tax income inequality by even a little more. Germany experienced an increase in the wage tax and a reduction in the capital income tax. As we can see in the bottom panel of Fig. 3, the labor supply falls and the capital stock increases in response to these changes. Since the effect on hours work is stronger, the overall impact is to reduce output. The effect on the distribution of wealth is almost negligible, hence the dynamics of income inequality are driven by the equalizing effect of fewer working hours (equivalent to that observed in the simulation for France) and the reverse redistribution entailed by the new taxes (as the wage income tax now exceeds the capital income tax). The second effect dominates and post-tax income inequality rises by about $2 \%$.

As a description of reality this exercise must be viewed with caution. For example, while we have assumed that the tax changes occurred immediately, in fact they were introduced gradually over a substantial period of time, so that what Carey and Rabesona (2004) report are the accumulated changes. Moreover, other structural changes, such as productivity increases are also obviously relevant. It is clear that while average hours worked declined in Europe, output and capital stock increased. Rerunning the simulations, with the productivity parameter $A$ simultaneously 
increasing by say $40 \%$ in conjunction with the tax changes, we find that output and capital in France and Germany substantially increase, while for the Cobb-Douglas technology we are assuming, the decline in hours worked continues to apply. ${ }^{19}$

Our model also clearly abstracts from other important aspects of the distribution of income most notably differences in skills and in wage rates. Nevertheless the exercise just performed is broadly consistent with the evidence on inequality trends; see Atkinson (2007). As is well-known, disposable income inequality rose sharply in the US, with the Gini coefficient increasing by some 6 percentage points in the last three decades of the $20^{\text {th }}$ century. Germany also experienced an increase in the Gini coefficient over the period, although more moderate, while in France inequality fell between 1970 and 2000 by about 6 Gini points. ${ }^{20}$

\section{Concluding comments}

The neoclassical growth model is one of the cornerstones of modern macroeconomic policy analysis. Although the model has been extensively used to assess the impact of different forms of taxation on aggregate magnitudes, the implications of changes in tax rates on the distribution of income and wealth has received only limited attention. In this paper we have examined the distributional responses to tax changes in a neoclassical growth model in which agents differ in their initial wealth holdings.

The endogeneity of the labor supply plays a crucial role in our analysis. The key mechanism whereby the initial distribution of capital endowments influences the distribution of income is through the wealth effect, which implies that wealthier agents supply less labor, although the resulting distribution of labor supplies is less unequal than that of the capital endowments. Tax changes then have three distributional effects. First, during the transition to the new steady state, agents will accumulate capital at different rates, implying a change in the distribution of wealth. Second, tax changes have direct redistributive effects increasing or decreasing post-tax inequality for a given degree of pre-tax inequality. Third, higher taxes lead to a lower labor supply of all agents,

\footnotetext{
${ }^{19}$ The decline in output should therefore be interpreted as a (partial) ceteris paribus response rather than any prediction pertaining to the behavior of aggregate output.

${ }^{20}$ See also Alesina et al. (2005), who report a positive correlation between average hours worked in a country and the Gini coefficient of income for OECD economies.
} 
but reduce that of the capital-rich by more than that of the capital-poor. This results in a more dispersed distribution of labor incomes and, since they are negatively correlated with capital income, tends to reduce pre-tax income inequality.

We have illustrated the effect of policy by examining the distributional consequences of financing an increase in public spending through a variety of taxes. A clear trade-off between output and inequality appears, with the modes of finance that result in higher output leading also to greater inequality. When we examine the impact of an increase taxation that is used to finance transfers, the wage tax emerges as the least desirable policy: it reduces substantially the labor supply and hence output, and leads to an increase in post-tax income inequality. The alternative modes of finance present again a policy trade-off, with the capital tax resulting in a large fall in both output and inequality, while a higher consumption tax entails the smallest reduction in output but also in inequality.

Finally, we conclude with a number of caveats. First, the infinitely-lived agent framework abstracts from an important aspect of the evolution of the distribution of capital: the intergenerational transmission of wealth. As a result, our analysis does not examine the potential role of state taxes in determining distribution. This question has been addressed in other work that complements our approach. Second, we have assumed no differences in wage rates across agents, implying that the distribution of earnings depends exclusively on the distribution of hours of work. Allowing for differences in the earning capacity of agents and examining how earning capacity and wealth interact to determine labor supply is clearly an important question. Finally, the fact that the distributions of wealth and income depend upon the initial jump in the labor supply implies that they are path-dependent. This means that the distributional consequences of a fiscal shock (or any structural shock) will depend upon whether it all occurs immediately, as we have been assuming, or takes place over time. Further work is needed to understand these last two issues. 


\section{Appendix}

This Appendix is devoted to the derivation of several technical details

\section{A.1 Derivation of the macroeconomic equilibrium}

From the consumer problem in (3) and (4) we have the first-order conditions:

$$
\begin{aligned}
& C_{i}^{\gamma-1} l_{i}^{\eta \gamma} G^{\theta \gamma}=\left(1+\tau_{c}\right) \lambda_{i} \\
& \eta C_{i}^{\gamma} l_{i}^{\eta \gamma-1} G^{\theta \gamma}=w\left(1-\tau_{w}\right) \lambda_{i} \\
& r\left(1-\tau_{k}\right)-\delta=\beta-\frac{\dot{\lambda}_{i}}{\lambda_{i}}
\end{aligned}
$$

where $\lambda_{i}$ is agent $i$ 's shadow value of capital, together with the transversality condition

$$
\lim _{t \rightarrow \infty} \lambda_{i} K_{i} e^{-\beta t}=0
$$

From these equations we obtain

$$
\begin{gathered}
\eta \frac{C_{i}}{l_{i}}=w(K, l)\left(\frac{1-\tau_{w}}{1+\tau_{c}}\right) \\
(\gamma-1) \frac{\dot{C}_{i}}{C_{i}}+\eta \gamma \frac{\dot{l}_{i}}{l_{i}}+\theta \gamma \frac{\dot{Y}}{Y}=\frac{\dot{\lambda}_{i}}{\lambda_{i}}=\beta+\delta-r(K, L)\left(1-\tau_{k}\right)
\end{gathered}
$$

Taking the time derivative of (A.2) yields

$$
\frac{\dot{C}_{i}}{C_{i}}-\frac{\dot{l}_{i}}{l_{i}}=\frac{w_{K} K}{w} \frac{\dot{K}}{K}+\frac{w_{l} l}{w} \frac{\dot{l}}{l}
$$

This equation, together with (A.3), then implies

$$
\frac{\dot{C}_{i}}{C_{i}}=\frac{\dot{C}}{C} ; \quad \frac{i_{i}}{l_{i}}=\frac{i}{l} \quad \text { for all } i
$$

Now turn to the aggregates. Summing (A.2), (A.4) and (7) over all agents, we get

$$
\eta \frac{C}{l}=w(K, l)\left(\frac{1-\tau_{w}}{1+\tau_{c}}\right)
$$




$$
\begin{aligned}
& (\gamma-1) \frac{\dot{C}}{C}+\eta \gamma \frac{\dot{l}}{l}+\theta \gamma \frac{\dot{Y}}{Y}=\beta+\delta-r(K, l)\left(1-\tau_{k}\right) \\
& \frac{\dot{C}}{C}=\frac{w_{K} K}{w} \frac{\dot{K}}{K}+\left(1+\frac{w_{l} l}{w}\right) \frac{\dot{l}}{l} \\
& \frac{\dot{K}}{K}=r(K, l)\left(1-\tau_{k}\right)-\delta+\frac{w(K, l)\left(1-\tau_{w}\right)}{K}\left(1-l \frac{1+\eta}{\eta}\right)+\frac{T}{K}
\end{aligned}
$$

To obtain the macrodynamic equilibrium conditions (11) we substitute (2a) and (2b), together with the government budget constraint (8) into (A.9) from which (11a) immediately follows. To obtain (11b) we first take the time derivative of the aggregate production function (1)

$$
\dot{Y}=F_{K} \dot{K}+F_{L} \dot{L}
$$

implying

$$
\frac{\dot{Y}}{Y}=\frac{F_{K} K}{Y} \frac{\dot{K}}{K}-\frac{F_{L} l}{Y} \frac{i}{l}
$$

Combining (A.7), (A.8), (A.10), and the product market equilibrium condition (11a) yields (11b)

\section{A.2 Linearization of the aggregate dynamic system}

Linearizing eqs. (11a) and (11b) around the steady state yields the local dynamics for $K$ and $l$,

$$
\left(\begin{array}{c}
\dot{K} \\
\dot{l}
\end{array}\right)=\left(\begin{array}{ll}
a_{11} & a_{12} \\
a_{21} & a_{22}
\end{array}\right)\left(\begin{array}{c}
K-\tilde{K} \\
l-\tilde{l}
\end{array}\right)
$$

where

$$
a_{11}=(1-g) F_{K}-\delta-F_{K L} \frac{l}{\eta} \frac{1-\tau_{w}}{1+\tau_{c}} ; \quad a_{12}=-F_{L}\left((1-g)+\frac{1}{\eta} \frac{1-\tau_{w}}{1+\tau_{c}}\right)+F_{L L} \frac{l}{\eta} \frac{1-\tau_{w}}{1+\tau_{c}}<0 ;
$$

$$
\begin{aligned}
& a_{21}=\frac{1}{H(l)}\left[F_{K K}\left(1-\tau_{k}\right)-\left((1-\gamma) \frac{F_{K L}}{F_{L}}-\theta \gamma \frac{F_{K}}{F}\right) a_{11}\right] ; \\
& a_{22}=\frac{1}{H(l)}\left[-F_{K L}\left(1-\tau_{k}\right)-\left((1-\gamma) \frac{F_{K L}}{F_{L}}-\theta \gamma \frac{F_{K}}{F}\right) a_{12}\right]
\end{aligned}
$$

and

$$
H \equiv \frac{1-\gamma(1+\eta)}{l}-\left(\frac{(1-\gamma) F_{L L}}{F_{L}}-\theta \gamma \frac{F_{L}}{F}\right)
$$


By direct calculation we can show that

$$
\Gamma \equiv a_{11} a_{22}-a_{12} a_{21}=\frac{\left(1-\tau_{k}\right) F_{K K}}{H}\left[\frac{(1-g) F-\delta K}{L}+\frac{F_{L}}{\eta}\left(1-\tau_{l}\right)\right]
$$

Substituting (13) and simplifying yields

$$
\Gamma=\frac{\left(1-\tau_{k}\right)\left(1-\tau_{l}\right) F_{K K} F_{L}}{H \tilde{L} \eta}
$$

In order for $\Gamma<0$ and for the equilibrium to be a saddlepoint, we require $H>0$, a condition that holds if $\theta$ is not too large, and we assume to be met.

We immediately see that $a_{12}<0$. In order to determine the likely signs of the other elements, it is useful to express them in terms of dimensionless quantities such as the elasticity of substitution in production, $\varepsilon \equiv F_{K} F_{L} / F F_{K L}$ and $s \equiv F_{K} K / F$, the share of output going to capital. Thus, using the steady-state equilibrium conditions, we may write

$$
\begin{aligned}
& a_{11}=\frac{(1-g)(\varepsilon-1)(\beta+\delta)-\delta(\varepsilon-\tilde{s})\left(1-\tau_{k}\right)}{\varepsilon\left(1-\tau_{k}\right)} \\
& a_{21}=\frac{F_{K K}}{H F_{K}}\left\{(\beta+\delta)+a_{11} \frac{\tilde{s}}{1-\tilde{s}}[1-\gamma(1+\theta \varepsilon)]\right\} \\
& a_{22}=-\frac{1}{H}\left\{F_{K L}\left(1-\tau_{k}\right)+a_{12}\left[(1-\gamma) \frac{F_{K L}}{F_{L}}-\theta \gamma \frac{F_{K}}{F}\right]\right\}
\end{aligned}
$$

the signs of which involve tradeoffs between $\varepsilon$ and the other parameters. From (A.11c) we immediately find that our assumption $\gamma<0$ is sufficient to ensure that $a_{22}>0$, implying $\mu-a_{22}<0$. In the case of the Cobb-Douglas production function, $a_{11}<0$, while

$$
\operatorname{sgn}\left(a_{21}\right)=\operatorname{sgn}(\delta s[1-\gamma(1+\theta)]-(\beta+\delta))
$$

This is certainly negative if either $\delta=0$ (no depreciation) or $\gamma=0$ (logarithmic utility). It is also negative for the parameter set employed in our numerical simulations: $\beta=0.04, \delta=0.04, \gamma=-1.5$, $s=0.4$. 


\section{References}

Aghion, P., E. Caroli, and C. García-Peñalosa, 1999. Inequality and growth in the new growth theories. Journal of Economic Literature 37, 1615-69.

Alesina, A., E.L. Glasser and B. Sacerdote, 2005. Work and leisure in the US and Europe: Why so different?, NBER Macroeconomics Annual, 1-64.

Algan, Y., A. Cheron, J-O. Hairault, and F. Langot, 2003. Wealth effect on labor market transitions. Review of Economic Dynamics 6, 156-178.

Alvarez-Peláez, M.J. and A. Díaz, 2005. Minimum consumption and transitional dynamics in wealth distribution. Journal of Monetary Economics 52, 633-67.

Atkinson, A.B. 2007. Distribution and growth in Europe - the empirical picture: A long-run view of the distribution of income. Mimeo, Nuffield College, Oxford.

Benhabib, J. And A. Bisin, 2006. The Distribution of Wealth and Redistributive Policies. Unpublished working paper NYU.

Bertola, G., R. Foellmi, and J. Zweimüller, 2006. Income Distribution in Macroeconomic Models. Princeton University Press, Princeton NJ.

Carey, D. and J. Rabesona, 2004. Tax ratios on labor and capital income and Consumption. In P.B. Sorensen (ed.), Measuring the Tax Burden on Capital and Labor, CESifo seminar series, MIT Press: Cambridge, Ma., 213-62.

Caselli, F., and J. Ventura, 2000. A representative consumer theory of distribution. American Economic Review 90, 909-926.

Castañeda, A., J. Díaz-Giménez, and V. Rios-Rull, 1998. Exploring the income distribution business cycle dynamics. Journal of Monetary Economics, 42, 93-130.

Chamley, C. 1986. Optimal taxation of capital income in General Equilibrium with Infinite Lives. Econometrica 54, 607-622.

Chatterjee, S. and B. Ravikumar, 1999. Minimum consumption requirements: Theoretical and quantitative implications for growth and distribution. Macroeconomic Dynamics 3, 482-505.

Chatterjee, S., 1994. Transitional dynamics and the distribution of wealth in a neoclassical growth model. Journal of Public Economics 54, 97-119. 
Cheng, I-H. and E. French, 2000. The effect of the run-up in the stock market on labor supply. Federal Reserve Bank of Chicago Economic Perspectives 24, 48-65.

Coronado, J.L. and M. Perozek, 2003. Wealth effects and the consumption of leisure: Retirement decisions during the stock market boom of the 1990s. Board of Governors of the Federal Reserve System, Finance and Economics Discussion Series, 2003-20.

Correia, I.H., 1999. On the efficiency and equity trade-off. Journal of Monetary Economics 44, 581603.

Diaz, A., J. Pijoan-Mas, and V. Rios-Rull, 2003. Habit formation: Implications for the wealth distribution. Journal of Monetary Economics, 50, 1257-1291.

Eisenberg, B., 1961. Aggregation of utility function. Management Science 7, 337-350.

García-Peñalosa, C. and S.J. Turnovsky, 2007. Growth, income inequality and fiscal policy: What are the relevant tradeoffs? Journal of Money, Credit and Banking 39, 369-394.

Gorman, W., 1953. Community preference fields. Econometrica 21, 63-80.

Guvenen, F., 2006. Reconciling conflicting evidence on the elasticity of intertemporal substitution: A macroeconomic perspective. Journal of Monetary Economics 53, 1451-1472.

Holtz-Eakin, D., D. Joulfaian, and H.S. Rosen, 1993. The Carnegie conjecture: Some empirical evidence. Quarterly Journal of Economics 108, 413-435.

Judd, K.L. 1985, Redistributive taxation in a simple perfect foresight model. Journal of Public Economics 28, 59-81.

Krusell, P., and A. Smith, 1998. Income and wealth heterogeneity in the macroeconomy. Journal of Political Economy 106, 867-896.

Krusell, P., V. Quadrini, and V. Rios-Rull, 1996. Are consumption taxes really better than income taxes? Journal of Monetary Economics 37, 475-504.

Ladrón-de-Guevara, A., Ortigueira, S., and Santos, M. S., 2002. Equilibrium dynamics in a twosector model with taxes. Journal of Economic Theory 105, 99-119.

Lucas, R.E., 1990. Supply-side economics: An analytical review. Oxford Economic Papers 42, 293316. 
MaCurdy, T., 1981. An empirical model of labor supply in a life cycle setting. Journal of Political Economy 89, 1059-1085.

Maliar, L. and S. Maliar, 2001. Heterogeneity in capital and skills in a neoclassical stochastic growth model. Journal of Economic Dynamics and Control 38, 635-654.

Obiols-Homs, F. and C. Urrutia, 2005. Transitional dynamics and the distribution of assets. Economic Theory 25, 381-400.

Ortigueira, S., 2000. A dynamic analysis of an endogenous growth model with leisure. Economic Theory 16, 43-62.

Prescott, E.C., 2004. Why do Americans work so much more than Europeans? Federal Reserve Bank of Minneapolis Quarterly Review 28, 2-13.

Sorger, G., 2000. Income and wealth distribution in a simple growth model. Economic Theory 16, 23-42.

Stiglitz, J.E., 1969. The distribution of income and wealth among individuals. Econometrica 37, 38297.

Stokey, N.L. and S. Rebelo. 1991. Growth Effects of Flat tax Rates. Journal of Political Economy 103, 519-550.

Turnovsky, S.J., 1995. Methods of Macroeconomic Dynamics. MIT Press, Cambridge, MA.

Turnovsky, S.J., 2000. Fiscal policy, elastic labor supply, and endogenous growth. Journal of Monetary Economics 45, 185-210.

Turnovsky, S.J. and C. García-Peñalosa, 2008. Distributional dynamics in a neoclassical growth model: The role of elastic labor supply. Journal of Economic Dynamics and Control, 32, 1399-1431.

Wang, N. 2007. An equilibrium model of wealth distribution. Journal of Monetary Economics 54, 1882-1904. 
Table 1

Long-run Fiscal Changes (lump-sum tax-financed)

\begin{tabular}{|c|c|c|c|c|}
\hline & $g$ & $\tau_{c}$ & $\tau_{w}$ & $\tau_{k}$ \\
\hline$\frac{d \tilde{K}}{\tilde{K}}$ & $\frac{\tilde{F} \tilde{l}}{\tilde{C}}>0$ & $-\frac{\tilde{l}}{1+\tau_{c}}<0$ & $-\frac{\tilde{l}}{1-\tau_{w}}<0$ & $-\frac{\tilde{F}_{K}}{\tilde{K} D}\left[\tilde{C}\left(\frac{1}{\tilde{l}}+\frac{\tilde{s}}{\varepsilon \tilde{L}}\right)+\tilde{F}_{L}(1-g)\right]<0$ \\
\hline$\frac{d \tilde{L}}{\tilde{L}}$ & $\frac{\tilde{F} \tilde{l}}{\tilde{C}}>0$ & $-\frac{\tilde{l}}{1+\tau_{c}}<0$ & $-\frac{\tilde{l}}{1-\tau_{w}}<0$ & $\frac{1}{\tilde{L} D \varepsilon}\left[(1-g) \tilde{F}_{K}(\varepsilon-1)-\delta(\varepsilon-\tilde{s})\right]$ \\
\hline$\frac{d \tilde{Y}}{\tilde{Y}}$ & $\frac{\tilde{F} \tilde{l}}{\tilde{C}}>0$ & $-\frac{\tilde{l}}{1+\tau_{c}}<0$ & $-\frac{\tilde{l}}{1-\tau_{w}}<0$ & $-\frac{\tilde{F}_{K}}{\tilde{Y} D}\left[\tilde{F}_{K} \tilde{C}\left(\frac{1}{\tilde{l}}+\frac{1}{\varepsilon \tilde{L}}\right)+\tilde{F}_{L} \delta\right]<0$ \\
\hline$\frac{d \tilde{s}}{\tilde{s}}$ & 0 & 0 & 0 & $\frac{1-\varepsilon}{\left(1-\tau_{k}\right)}$ \\
\hline$d \tilde{\sigma}_{k}$ & - & + & + & + \\
\hline$d \tilde{\varphi}$ & $\left(\frac{\eta}{(1+\eta)}\right)\left(\frac{1+\tau_{c}}{1-\tau_{w}}\right)>0$ & $-\frac{\tilde{F}_{L} \tilde{l}}{\tilde{F}(1+\eta)\left(1+\tau_{c}\right)}<0$ & $-\frac{\tilde{F}_{L} \tilde{l}}{\tilde{F}(1+\eta)\left(1-\tau_{w}\right)}<0$ & $\begin{aligned} \frac{1}{(1+\eta) \tilde{L}}\left[\frac{\tilde{s}(1-\varepsilon)}{\left(1-\tau_{k}\right)}\right. & \\
& \left.+(1-\tilde{s}) \frac{\partial \tilde{L} / \partial \tau_{k}}{\tilde{L}}\right]\end{aligned}$ \\
\hline$d \tilde{\psi}$ & $\left(\frac{\eta}{(1+\eta)}\right) \frac{\left(1+\tau_{c}\right)}{\left(\tilde{Y}^{a} / \tilde{Y}\right)}>0$ & $-\left(\frac{\eta}{1+\eta}\right) \frac{\tilde{C}}{\tilde{F}\left(\tilde{Y}_{a} / \tilde{Y}\right)}$ & $\begin{array}{l}\frac{\tilde{s}\left(1-\tau_{k}\right)(1-\tilde{\varphi})}{\left(\tilde{Y}_{a} / \tilde{Y}\right)^{2}} \\
\quad+\frac{\left(1-\tau_{w}\right)}{\left(\tilde{Y}_{a} / \tilde{Y}\right)} \frac{\partial \tilde{\varphi}}{\partial \tau_{w}}\end{array}$ & $\begin{array}{c}\frac{\tilde{s}\left(1-\tau_{k}\right)(1-\tilde{\varphi})}{\left(\tilde{Y}_{a} / \tilde{Y}\right)^{2}}\left(\frac{\left(\tau_{w}-\tau_{k}\right)(1-\varepsilon)}{\left(1-\tau_{k}\right)}-1\right) \\
+\frac{\left(1-\tau_{w}\right)}{\left(\tilde{Y}_{a} / \tilde{Y}\right)} \frac{\partial \tilde{\varphi}}{\partial \tau_{k}}\end{array}$ \\
\hline
\end{tabular}

$D \equiv-\frac{\left(1-\tau_{k}\right) \tilde{F}_{K K} \tilde{C}}{\tilde{L} \tilde{l}}>0 ; \quad \tilde{Y}_{a} / \tilde{Y} \equiv\left(1-\tau_{k}\right) \tilde{s}+\left(1-\tau_{w}\right)(1-\tilde{s})$ 
Table 2

Alternative modes of financing increases in government expenditure

\begin{tabular}{|c|c|c|c|c|c|c|}
\hline & $\begin{array}{l}\text { Lump-sum tax } \\
g\end{array}$ & $\begin{array}{c}\text { Cons. tax } \\
\tau_{c}\end{array}$ & Wag & $\tau_{w}$ & & $\begin{array}{l}\text { Capital income tax } \\
\tau_{k}\end{array}$ \\
\hline$\frac{d \tilde{K}}{\tilde{K}}$ & $\frac{\eta \tilde{L}}{1-\tilde{s}}>0$ & 0 & $\frac{1+\eta}{1-\tilde{s}}$ & {$\left[\frac{\eta}{1+\eta}-\tilde{l}\right]$} & $<0$ & $\begin{array}{l}\frac{1}{1-\tilde{s}}\left\{(1+\eta)\left[\frac{\eta}{1+\eta}-\tilde{l}\right]\right. \\
\left.\quad+\frac{F_{L}}{\tilde{F}_{L L}}[1+\eta(1-g)]\right\}<0\end{array}$ \\
\hline$\frac{d \tilde{L}}{\tilde{L}}$ & $\frac{\eta \tilde{L}}{1-\widetilde{s}}>0$ & 0 & $\frac{1+\eta}{1-\tilde{s}}$ & {$\left[\frac{\eta}{1+\eta}-\tilde{l}\right]$} & $<0$ & $\begin{array}{l}\frac{1}{1-\tilde{s}}\left\{\left(1+\eta\left[\frac{\eta}{1+\eta}-\tilde{l}\right]\right.\right. \\
\left.\quad+\frac{\eta}{\tilde{F}_{K L}}\left[(1-g) \tilde{F}_{K}-\delta\right]\right\}\end{array}$ \\
\hline$\frac{d \tilde{Y}}{\tilde{Y}}$ & $\frac{\eta \tilde{L}}{1-\tilde{s}}>0$ & 0 & $\frac{1+\eta}{1-\tilde{s}}$ & {$\left[\frac{\eta}{1+\eta}-\tilde{l}\right]$} & $<0$ & $\begin{array}{r}\frac{1+\eta}{1-\tilde{s}}\left[\frac{\eta}{1+\eta}-\tilde{l}\right] \\
-\frac{1}{\tilde{F}_{K L} \tilde{F}}\left[\tilde{F}_{K}+\delta \eta\right]<0\end{array}$ \\
\hline$\frac{d \tilde{s}}{\tilde{s}}$ & 0 & 0 & & 0 & & $\frac{(1-\varepsilon)}{\tilde{s}}$ \\
\hline$d \tilde{\sigma}_{k}$ & - & 0 & & + & & + \\
\hline$d \tilde{\varphi}$ & $\frac{\eta}{1+\eta}>0$ & 0 & $\frac{1}{\tilde{L}}\left[\frac{1}{1}\right.$ & $\left.\frac{\eta}{1+\eta}-\tilde{l}\right]<$ & $<0$ & $\begin{array}{l}\frac{\eta}{1+\eta} \\
+\frac{1}{(1+\eta) \tilde{L}}\left[(1-\varepsilon)+\frac{(1-\tilde{s})}{\tilde{s}} \frac{\partial \tilde{L} / \partial \tau_{k}}{\tilde{L}}\right.\end{array}$ \\
\hline$d \tilde{\psi}$ & $\frac{\eta}{1+\eta}>0$ & 0 & $\frac{\tilde{s}(1-\tilde{\varphi})}{(1-\tilde{s})}+$ & $+\frac{1}{\tilde{L}}\left[\frac{\eta}{1+\eta}\right.$ & & $\begin{array}{l}-(1-\tilde{\varphi})+\frac{\eta}{1+\eta} \\
+\frac{1}{(1+\eta) \tilde{L}}\left[(1-\varepsilon)+\frac{(1-\tilde{s})}{\tilde{s}} \frac{\partial \tilde{L} / \partial \tau_{k}}{\tilde{L}}\right.\end{array}$ \\
\hline
\end{tabular}


Table 3: Increase in government expenditure

(increase in $g$ by 5 percentage points from 0.15 to 0.20 )

\begin{tabular}{|c|c|c|c|c|c|c|}
\hline & $\tilde{L}$ & $\tilde{K}$ & $\tilde{Y}$ & $\sigma_{k}$ & $\sigma_{y}$ & $\sigma_{y, a}$ \\
\hline $\begin{array}{c}\text { Base: } \\
\tau=0.0776, \tau_{w}=0.20, \\
\tau_{k}=0.20, \quad \tau_{c}=0.04\end{array}$ & $\mathbf{0 . 2 7 7}$ & $\mathbf{3 . 7 7 7}$ & $\mathbf{0 . 9 4 4}$ & $\mathbf{1}$ & $\mathbf{0 . 2 1 1}$ & $\mathbf{0 . 2 1 1}$ \\
\hline $\begin{array}{c}\text { Lump-sum tax financed } \\
\tau=0.0256\end{array}$ & $\begin{array}{c}0.292 \\
(+5.53 \%)\end{array}$ & $\begin{array}{c}3.986 \\
(+5.53 \%)\end{array}$ & $\begin{array}{c}0.997 \\
(+5.53 \%)\end{array}$ & $\begin{array}{c}0.9942 \\
(-0.58 \%)\end{array}$ & $\begin{array}{c}0.251 \\
(+19.0 \%)\end{array}$ & $\begin{array}{c}0.251 \\
(+19.0 \%)\end{array}$ \\
\hline $\begin{array}{c}\text { Wage income tax fin. } \\
\tau_{w}=0.287\end{array}$ & $\begin{array}{c}0.269 \\
(-2.82 \%)\end{array}$ & $\begin{array}{c}3.670 \\
(-2.82 \%)\end{array}$ & $\begin{array}{c}0.917 \\
(-2.82 \%)\end{array}$ & $\begin{array}{c}1.0026 \\
(+0.26 \%)\end{array}$ & $\begin{array}{c}0.189 \\
(-10.4 \%)\end{array}$ & $\begin{array}{c}0.226 \\
(+7.12 \%)\end{array}$ \\
\hline $\begin{array}{c}\text { Capital income tax fin. } \\
\tau_{k}=0.327\end{array}$ & $\begin{array}{c}0.284 \\
(+2.53 \%)\end{array}$ & $\begin{array}{c}2.903 \\
(-23.1 \%)\end{array}$ & $\begin{array}{c}0.863 \\
(-8.58 \%)\end{array}$ & $\begin{array}{c}1.0291 \\
(+2.91 \%)\end{array}$ & $\begin{array}{c}0.238 \\
(+12.8 \%)\end{array}$ & $\begin{array}{c}0.184 \\
(-12.8 \%)\end{array}$ \\
\hline
\end{tabular}

Table 4: Increase in Tax Rates

(used to finance an increase in the transfer by 5 percentage points)

\begin{tabular}{|c|c|c|c|c|c|c|}
\hline & $\tilde{L}$ & $\tilde{K}$ & $\tilde{Y}$ & $\sigma_{k}$ & $\sigma_{y}$ & $\sigma_{y, a}$ \\
\hline Base: & $\mathbf{0 . 2 7 7}$ & $\mathbf{3 . 7 7 7}$ & $\mathbf{0 . 9 4 4}$ & $\mathbf{1}$ & $\mathbf{0 . 2 1 1}$ & $\mathbf{0 . 2 1 1}$ \\
$\begin{array}{c}g=0.15, \tau_{w}=0.20, \\
\tau_{k}=0.20, \tau_{c}=0.04\end{array}$ & & & & & & \\
\hline Wage income tax incr. to & 0.255 & 3.484 & 0.871 & 1.0062 & 0.146 & 0.184 \\
$\tau_{w}=0.283$ & $(-7.75 \%)$ & $(-7.75 \%)$ & $(-7.75 \%)$ & $(+0.62 \%)$ & $(-30.8 \%)$ & $(-12.8 \%)$ \\
\hline $\begin{array}{c}\text { Cap. income tax incr. to } \\
\tau_{k}=0.323\end{array}$ & $\begin{array}{c}0.269 \\
(-2.89 \%)\end{array}$ & $\begin{array}{c}2.791 \\
(-26.1 \%)\end{array}$ & $\begin{array}{c}0.824 \\
(-12.7 \%)\end{array}$ & $\begin{array}{c}1.0283 \\
(+2.83 \%)\end{array}$ & $\begin{array}{c}0.196 \\
(-7.11 \%)\end{array}$ & $\begin{array}{c}0.142 \\
(-32.7 \%)\end{array}$ \\
\hline $\begin{array}{c}\text { Consumption tax incr. to } \\
\tau_{c}=0.112\end{array}$ & $\begin{array}{c}0.263 \\
(-4.78 \%)\end{array}$ & $\begin{array}{c}3.598 \\
(-4.78 \%)\end{array}$ & $\begin{array}{c}0.899 \\
(-4.78 \%)\end{array}$ & $\begin{array}{c}1.0042 \\
(+0.42 \%)\end{array}$ & $\begin{array}{c}0.172 \\
(-18.5 \%)\end{array}$ & $\begin{array}{c}0.172 \\
(-18.5 \%)\end{array}$ \\
\hline
\end{tabular}

Table 5: Policy parameters

\begin{tabular}{|ll|cccc|}
\hline & & $\tau_{k}$ & $\tau_{w}$ & $\tau_{c}$ & $g$ \\
\hline \multirow{2}{*}{ US: } & $\begin{array}{l}\text { initial } \\
\text { final }\end{array}$ & 0.28 & 0.20 & 0.05 & 0.22 \\
\cline { 2 - 5 } & & 0.23 & 0.21 & 0.05 & 0.22 \\
\hline \multirow{2}{*}{ France: } & $\begin{array}{l}\text { initial } \\
\text { final }\end{array}$ & 0.40 & 0.33 & 0.15 & 0.40 \\
\cline { 2 - 5 } & Germany: initial & 0.45 & 0.40 & 0.15 & 0.40 \\
\hline & final & 0.37 & 0.33 & 0.13 & 0.32 \\
\cline { 2 - 6 } & 0.35 & 0.35 & 0.13 & 0.32 \\
\hline
\end{tabular}




\section{Fig 1: Increase in G}

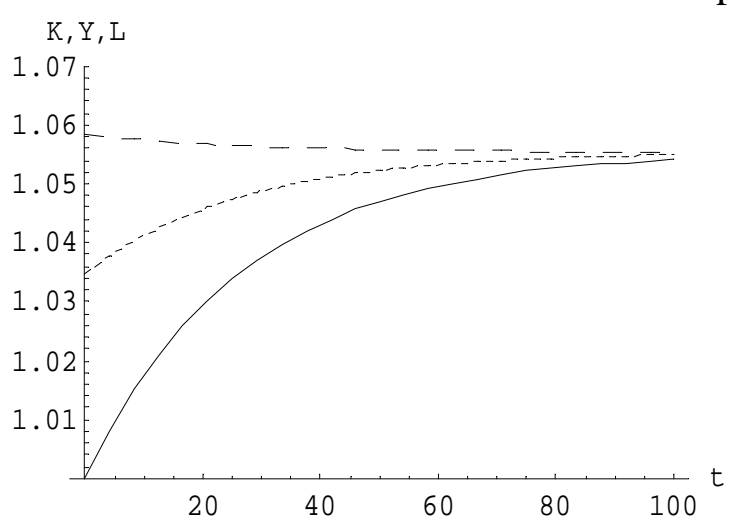

\section{Lump-sum tax financing}

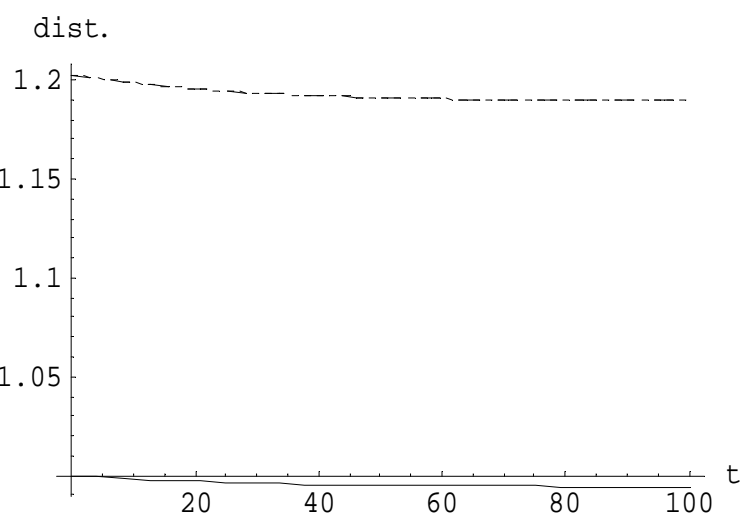

Wage income tax financing
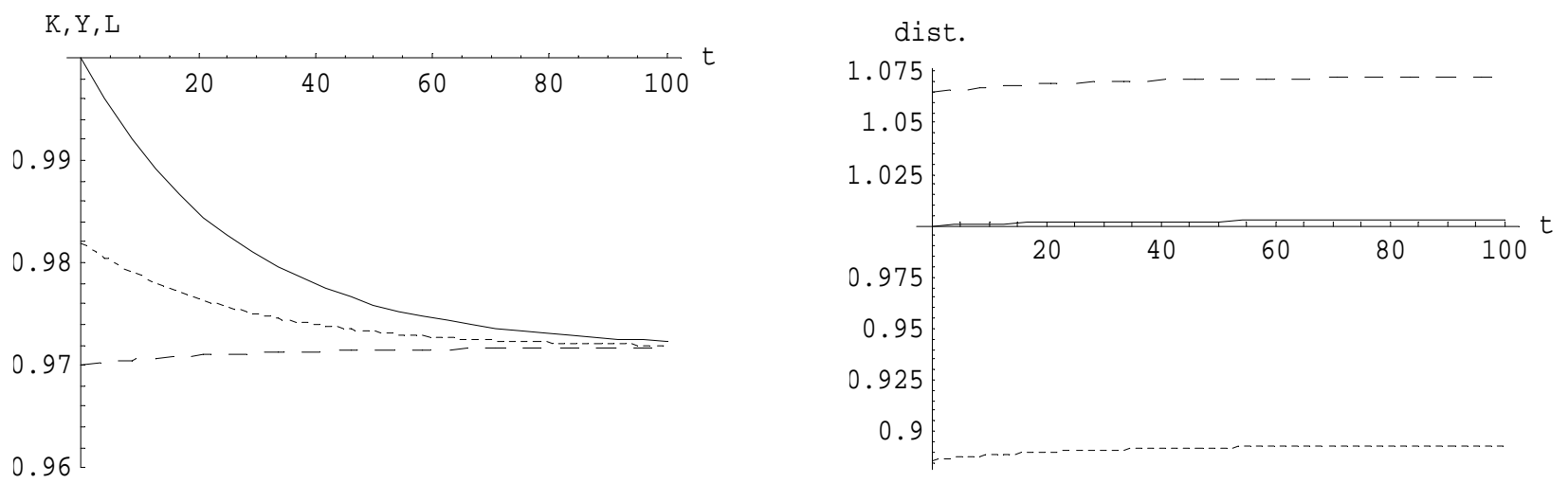

Capital income tax financing
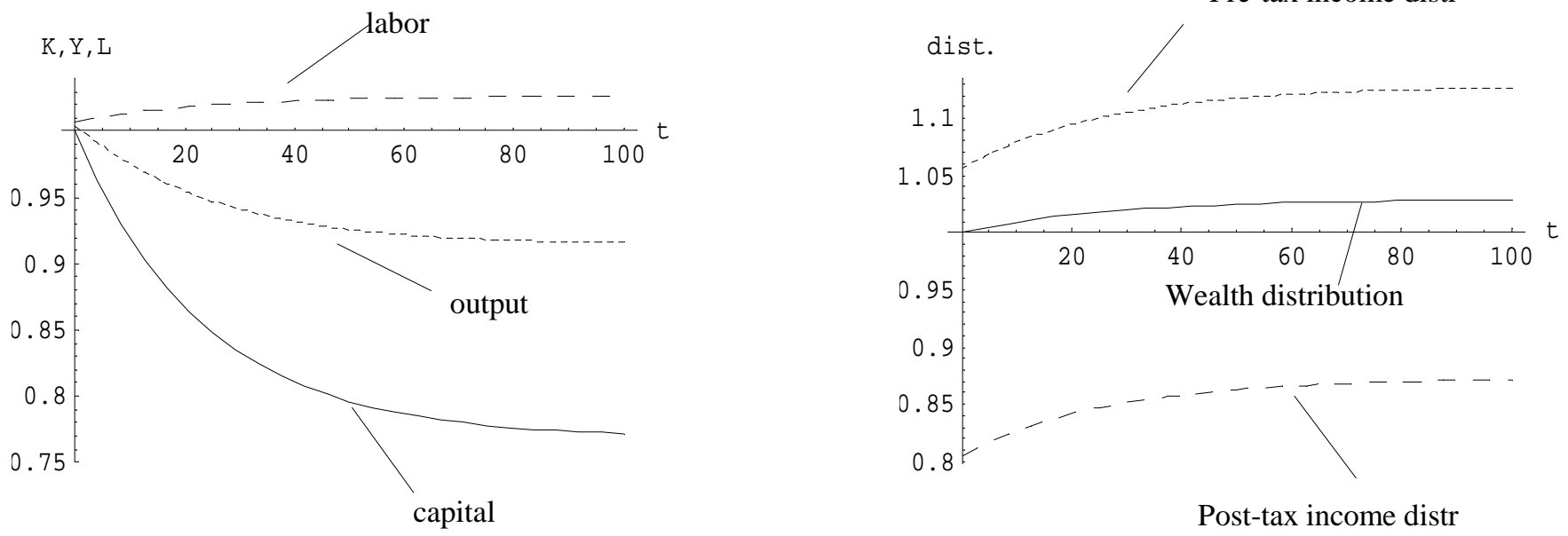

Post-tax income distr 
Fig 2: Increase in $\mathrm{T}$

Consumption tax financing
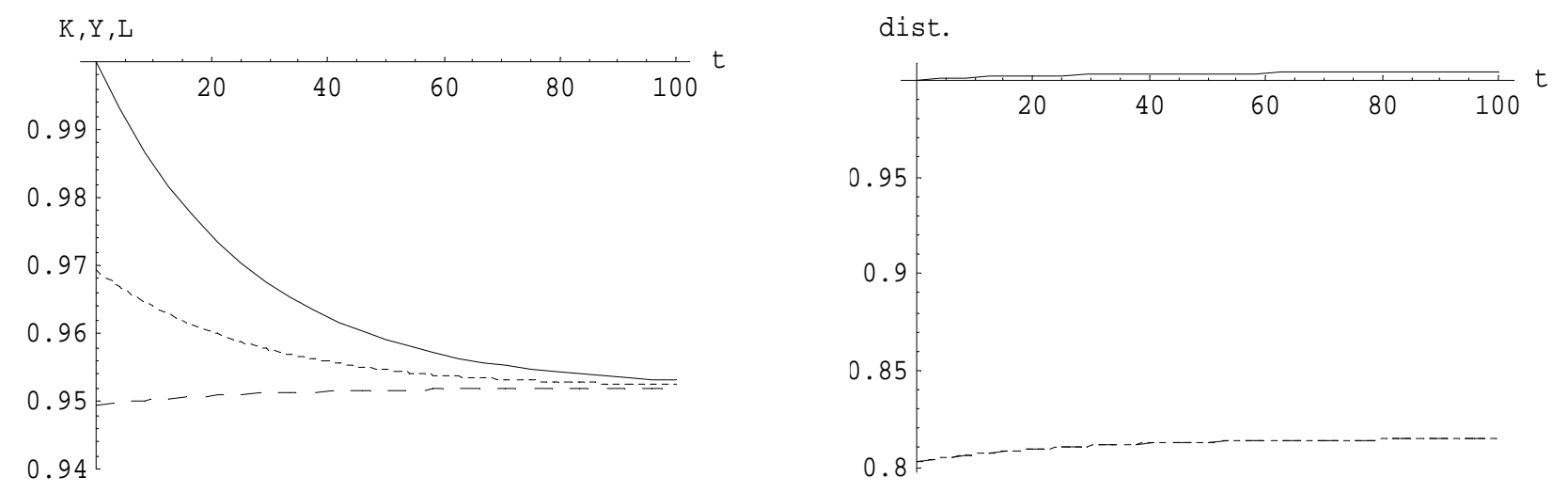

Wage income tax financing
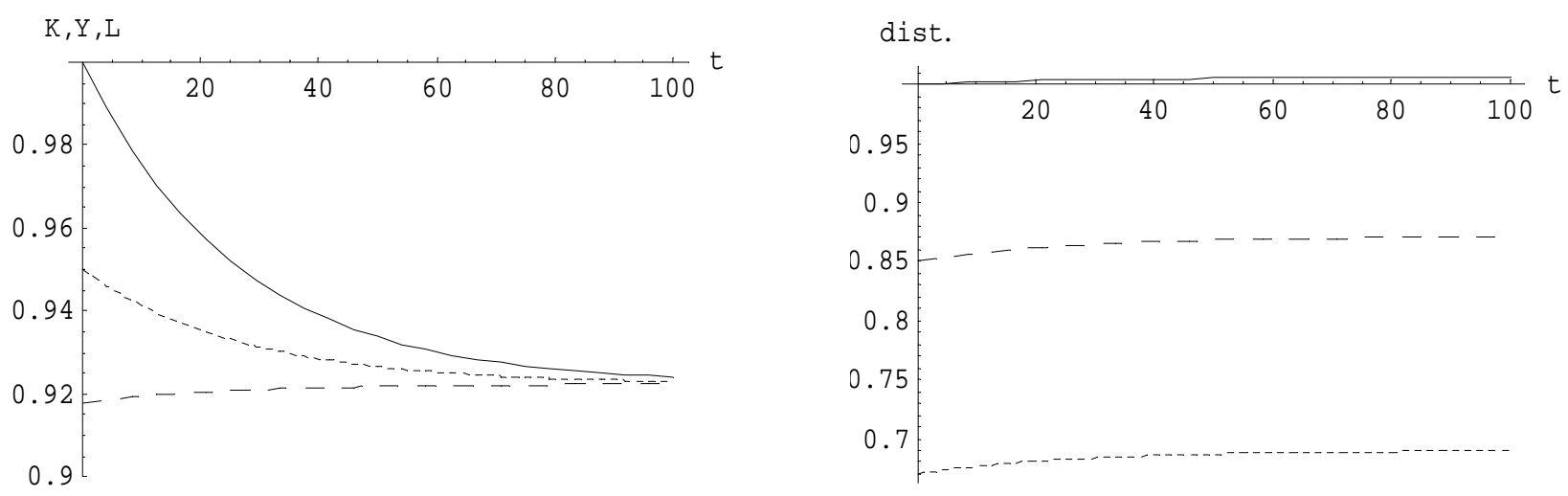

Capital income tax financing

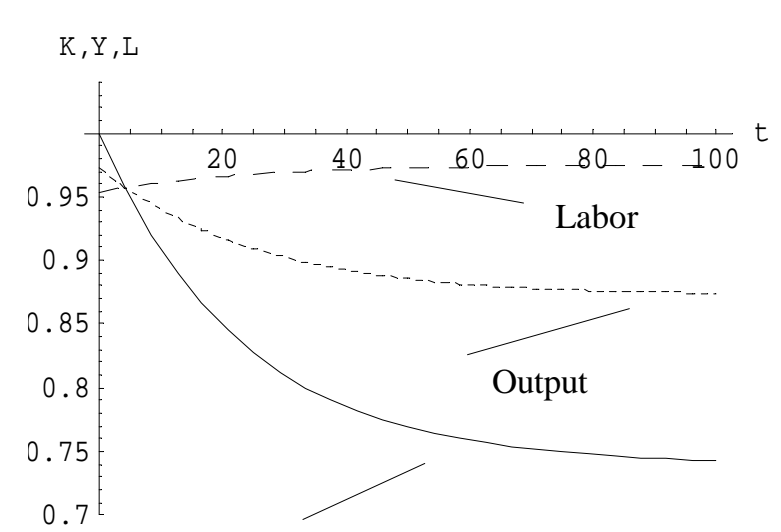

Capital

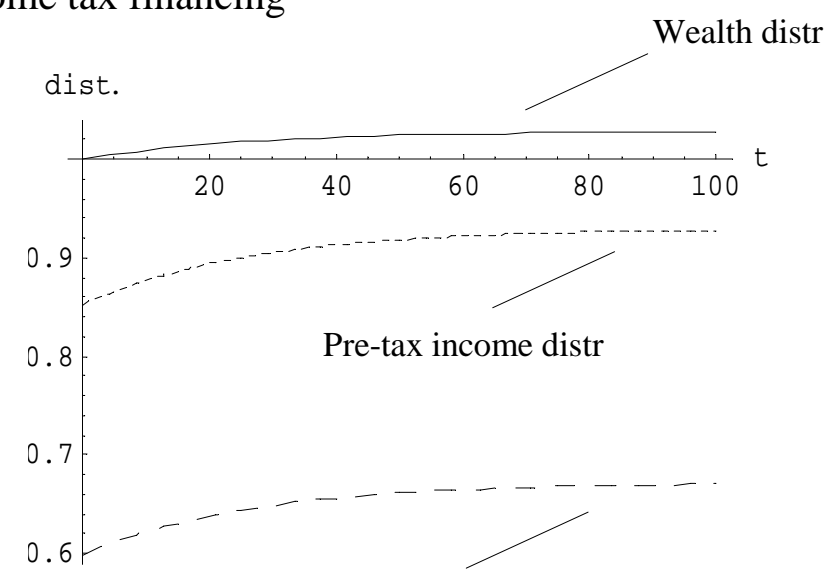

Post-tax income distr 


\section{Fig 3: Recent Experiences}

US
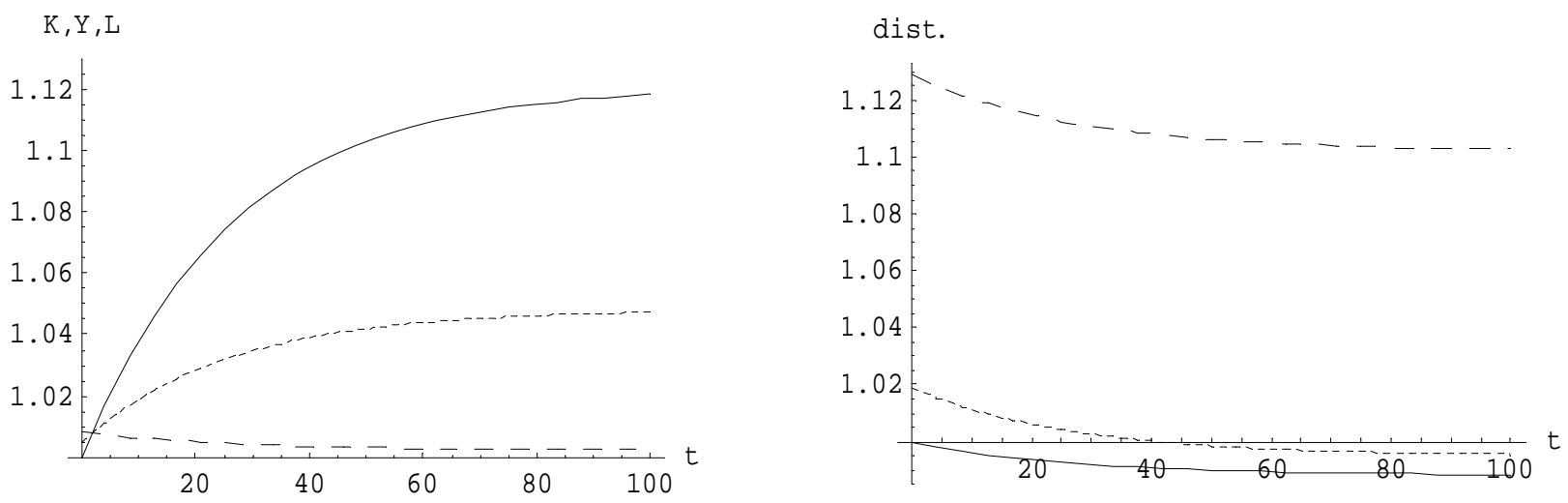

\section{France}
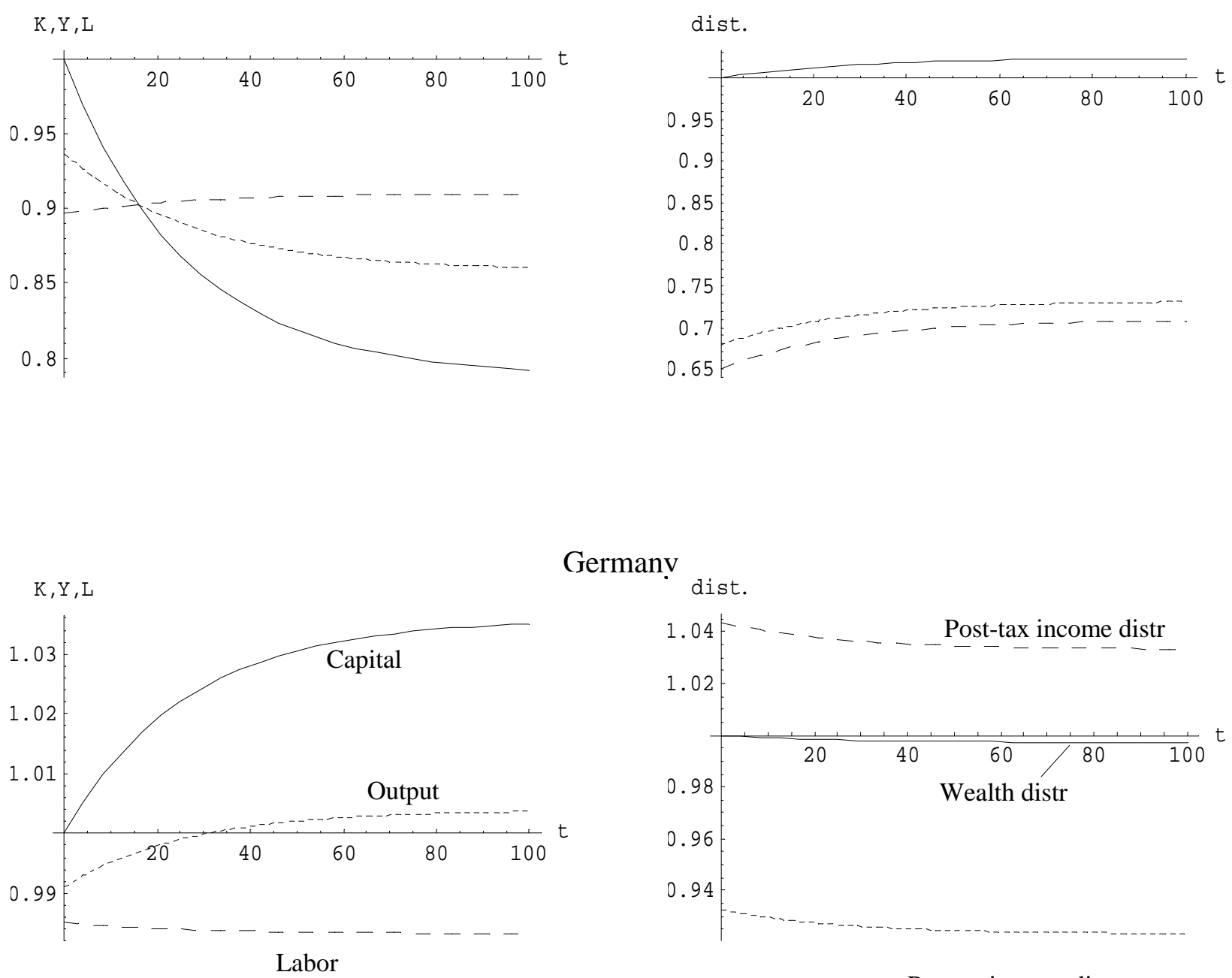

Pre-tax income distr 